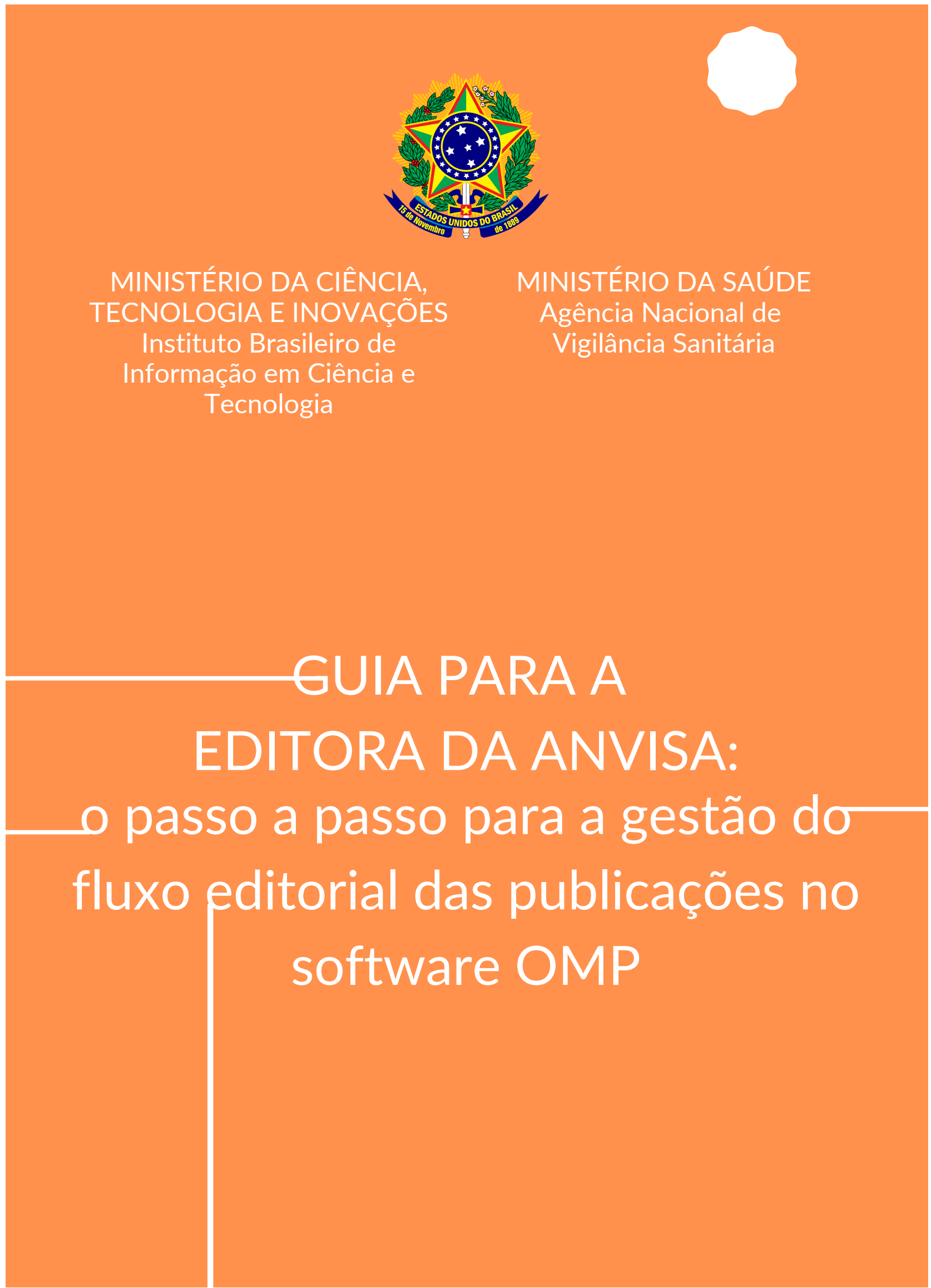




\section{PRESIDÊNCIA DA REPÚBLICA}

Jair Messias Bolsonaro

Presidente da República

Hamilton Mourão

Vice-Presidente da República

\section{MINISTÉRIO DA SAÚDE}

Eduardo Pazuello

Ministro da Saúde

AGÊNCIA NACIONAL DE VIGILÂNCIA SANITÁRIA

\section{Antonio Barra Torres}

Diretor-presidente/Primeira Diretoria

Meiruze Sousa Freitas

Segunda Diretoria

Cristiane Rose Jourdan Gomes

Terceira Diretoria

Romison Rodrigues Mota

Quarta Diretoria

Alex Machado Campos

Quinta Diretoria

\section{MINISTÉRIO DA CIÊNCIA, TECNOLOGIA E INOVAÇÓES}

Marcos Cesar Pontes

Ministro da Ciência, Tecnologia e

Inovações

INSTITUTO BRASILEIRO DE INFORMAÇÃ̃O EM CIÊNCIA E TECNOLOGIA

\section{Cecilia Leite Oliveira}

Diretora

Reginaldo de Araújo Silva

Coordenação de Administração - COADM

Gustavo Saldanha

Coordenação de Ensino e Pesquisa,

Ciência e Tecnologia da Informação COEPE

José Luis dos Santos Nascimento Coordenação de Planejamento, Acompanhamento e Avaliação - COPAV

Anderson Itaborahy

Coordenação-Geral de Pesquisa e Desenvolvimento de Novos Produtos CGNP

Bianca Amaro de Melo

Coordenação-Geral de Pesquisa e Manutenção de Produtos Consolidados CGPC

Tiago Emmanuel Nunes Braga Coordenação-Geral de Tecnologias de Informação e Informática - CGTI

Milton Shintaku

Coordenação de Tecnologias para Informação - COTEC 

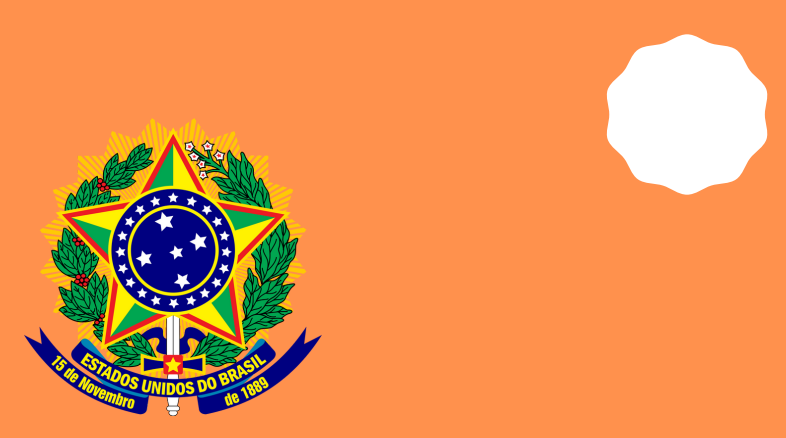

MINISTÉRIO DA CIÊNCIA, TECNOLOGIA E INOVAÇÕES

Instituto Brasileiro de

Informação em Ciência e

MINISTÉRIO DA SAÚDE Agência Nacional de Vigilância Sanitária

Tecnologia

\section{GUIA PARA A \\ EDITORA DA ANVISA: \\ o passo a passo para a gestão do \\ fluxo editorial das publicações no software OMP}

Fernanda Maciel Rufino Priscila Rodrigues dos Santos

Mariana Lozzi Teixeira

Milton Shintaku 
(c) 2021 Instituto Brasileiro de Informação em Ciência e Tecnologia - Ibict Esta obra é licenciada sob uma licença Creative Commons - Atribuição CC BY 4.0, sendo permitida a reprodução parcial ou total desde que mencionada a fonte.

\section{EQUIPE TÉCNICA}

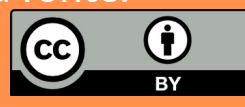

\section{Diretora do Instituto Brasileiro de Informação em Ciência e Tecnologia Cecilia Leite Oliveira}

Coordenador-Geral de Tecnologias de Informação e Informática - CGTI Tiago Emmanuel Nunes Braga

\section{Coordenador do Projeto}

Milton Shintaku

\section{Autores}

Fernanda Maciel Rufino

Priscila Rodrigues dos Santos

Mariana Lozzi Teixeira

Milton Shintaku

\author{
Revisão de texto \\ Mariana Lozzi Teixeira
}

Diagramação e projeto gráfico

Victor Ramos Silva

\section{Normalização}

Fernanda Maciel Rufino

Priscila Rodrigues dos Santos

\section{G943 \\ Guia para a editora da Anvisa: o passo a passo para a gestão do fluxo editorial das publicações no software OMP / Fernanda Maciel Rufino, Priscila Rodrigues dos Santos, Mariana Lozzi Teixeira e Milton Shintaku. -- Brasília: Ibict, 2021. \\ $70 \mathrm{p}$. \\ ISBN 978-65-89701-04-0 \\ DOI 10.18225/9786589701040 \\ 1. Editoração eletrônica. 2. Editores e edição. 3 Sistema de informação. 4. Software livre. I. Rufino, Fernanda Maciel. II. Santos, Priscila Rodrigues dos. III. Teixeira, Mariana Lozzi. IV. Shintaku, Milton. V. Instituto Brasileiro de Informação em Ciência e Tecnologia. VI. Título \\ CDU 004.4:027(083.131)}

Ficha catalográfica elaborada por Ingrid Torres SchiessI CRB1/3084

Esta produção é um produto do Projeto Estudos para implementação de Repositório Institucional na Biblioteca Terezinha Ayres Costa.

Ref. Processo SEI Nº 01302.000479/2018-80 (Processo de Contratação)

Ref. Processo SEI Nº1302.000437/2020-63 (Processo de Execução)

Ref. FUNDEP - 28139

As opiniões emitidas nesta publicação são de exclusiva e inteira responsabilidade dos autores, não exprimindo, necessariamente, o ponto de vista do Instituto Brasileiro de Informação em Ciência e Tecnologia ou do Ministério da Ciência, Tecnologia e Inovações. 


\section{SUMÁRIO}

\begin{tabular}{|c|c|}
\hline 1 APRESENTAÇÃO & 07 \\
\hline 2 INTRODUÇÃ̄o & 09 \\
\hline 3 OPEN MONOGRAPH PRESS & 11 \\
\hline 4 GADASTRO E SUBMISSÃO DE MANUSGRITO AO SISTEMA & 13 \\
\hline 4.1 REALZANDO LOGIN NO OMP & 14 \\
\hline 4.2 SUBMISSÃO & 14 \\
\hline 4.2.1 PREPARAR & 15 \\
\hline 4.2.2 ENVIAR & 18 \\
\hline 4.2.3 CATÁLOGO & 21 \\
\hline 4.2.4 CONFIRMAÇÃO & 28 \\
\hline 4.2.5 PRÓXIMOS PASSOS & 28 \\
\hline 5 REGEBIMENTO DA SUBMISSÃO & 30 \\
\hline 6 PARTICIPANTES & 32 \\
\hline 7 AGOMPANHAMENTO DO FLUXO EDITORIAL PELO EDITOR & 35 \\
\hline 7.1 AVALIAÇÃO & 37 \\
\hline 7.2 EDIÇÃO DE TEXTO & 44 \\
\hline 7.3 EDITORACG̃̃o & 49 \\
\hline 7.4 PUBLICACG̃̃̃ & 52 \\
\hline 7.4.1 TíTULO E RESUMO & 52 \\
\hline 7.4.2 CONTRIBUIIDORES & 54 \\
\hline
\end{tabular}




\section{SUMÁRIO}

7.4.3 CAṔ́TULOS

7.4.4 METADADOS

7.4.5 REFERÊNCIAS

57

7.4.6 IDENTIFICADORES

58

7.4.7 FORMATOS DE PUBLICACGÃO

58

7.4.8 CATÁLOGO

63

7.4.9 PERMISSÃO E DIVULGACÃ̃O

66

8 CONSIDERAÇÕES FINAIS

69 
O Guia para Editora da Agência Nacional de Vigilância Sanitária (ANVISA) compõe uma série de documentos técnicos desenvolvidos no âmbito do projeto de pesquisa firmado entre a ANVISA e o Instituto Brasileiro de Informação em Ciência e Tecnologia (Ibict). O Guia promove, entre outros pontos, estudos para proposição de uma editora para a Agência. Com isso, oferecer uma ferramenta para gerenciar o processo editorial do órgão, informatizando as atividades.

A solução encontrada pelo projeto está diretamente relacionada ao software Open Monograph Press (OMP), desenvolvido pelo Public Knowledge Project (PKP). Dentre as possibilidades oferecidas pela ferramenta foi explorada a criação de um portal de múltiplas editoras. Essa funcionalidade do software atenderia às necessidades da ANVISA, na medida em que possibilitaria hospedar no próprio sistema editoras de outras instituições, assim como permitiria que o órgão tivesse mais de uma editora. Outra vantagem atrelada ao OMP é permitir tanto o acesso aberto às publicações quanto a comercialização de livros.

O OMP informatiza as principais atividades relacionadas ao fluxo editorial de livros, desde a submissão dos manuscritos até a publicação do livro, em catálogos organizados. Com isso, a editora implementa um sistema informatizado com site que atende não apenas aos usuários como aos produtores e aos consumidores das obras da instituição. $O$ sistema possibilita, inclusive, a comercialização ou disponibilização das obras em texto integral gratuitamente. 
O presente guia não tem a intenção de ser extensivo, ou de encerrar todas as possibilidades oferecidas pelo software. Ele funciona, antes, com um documento inicial voltado à familiarização da ferramenta. Com isso, nosso objetivo é atender a implantação do OMP na editora da ANVISA, apresentando o passo a passo das principais funcionalidades oferecidas pelo sistema. Assim, pretendemos apoiar todo o processo, ofertando documentação técnica, alinhado às atividades de pesquisa e disseminação dos resultados, com transferência de tecnologia.

Por fim, espera-se atender aos objetivos iniciais do estudo considerando que a proposta de implantação de editora da ANVISA com o uso do OMP constitui um desafio que extrapola a implementação e o uso da ferramenta. A criação de uma editora em um órgão com o tamanho e a relevância da ANVISA passa por questões mais complexas, como a política editorial a ser adotada e questões relacionadas a direitos autorais. Desse modo, convidamos o leitor a pensar os processos editoriais de maneira integrada e tomar este Guia como o ponto de partida para a democratização do conhecimento. 
Publicações oficiais - aquelas publicadas por órgãos de governo - sempre foram constantes na administração pública. Por ano, muitos livros são publicados em todas as esferas e poderes. Dessa forma, torna-se inegável que o governo, como um todo, é um grande produtor de conhecimento. Apesar de manter um fluxo constante de publicações, não é garantido que todos esses trabalhos respeitem um processo editorial. Pelo contrário, muitos deles acontecem às margens de qualquer padrão, o que contribui para isolar o Brasil diante de padrões internacionais e dificultar o acesso às obras pela sociedade e, até, dentro dos próprios órgãos nas quais foram produzidas.

Pode-se notar que muitos órgãos de governo não contam com editora em sua estrutura organizacional. No entanto, publicam livros, muitos dos quais são produzidos inteiramente dentro dos órgãos. Devido à falta de padrões impostos, muitas das publicações governamentais podem não estar totalmente normalizadas conforme as regras oficiais para livros, nem mesmo ter registro oficial de publicação, como o International Standard Book Number (ISBN).

Assim, ter uma editora no órgão, mesmo que seja apenas como atribuição de uma unidade, garante seguimento de um fluxo editorial, possibilitando atendimento às normas de publicação. As atividades da editora podem ser atribuídas à biblioteca ou à comunicação social, ambas muito ligadas à disseminação da informação. Entretanto, ter um sistema informatizado possibilita que a execução das atividades 
editoriais seja mais facilmente realizada.

Nesse sentido, o OMP oferece às instituições ou órgãos de governo o sistema informatizado necessário para executar as tarefas editoriais para obras, como os livros. Trata-se de um software livre adequado aos órgãos públicos, pois não requer o pagamento de licenças e atende as necessidades para publicação de livros. O gerenciamento dos processos e tarefas requer, no entanto, conhecimento técnico e tecnológico por parte das equipes de editores e informáticos.

Outro trunfo do OMP é a sua versatilidade. O software se adequa a vários tipos de editora, mesmo que tenha sido desenvolvido para disseminação gratuita de conteúdos, e se mostrou bastante adequado aos órgãos públicos. Assim, oferece uma considerável gama de opções para que órgãos de governo implementem suas editoras e consequentemente fornecer fluxos editoriais para as suas publicações. 


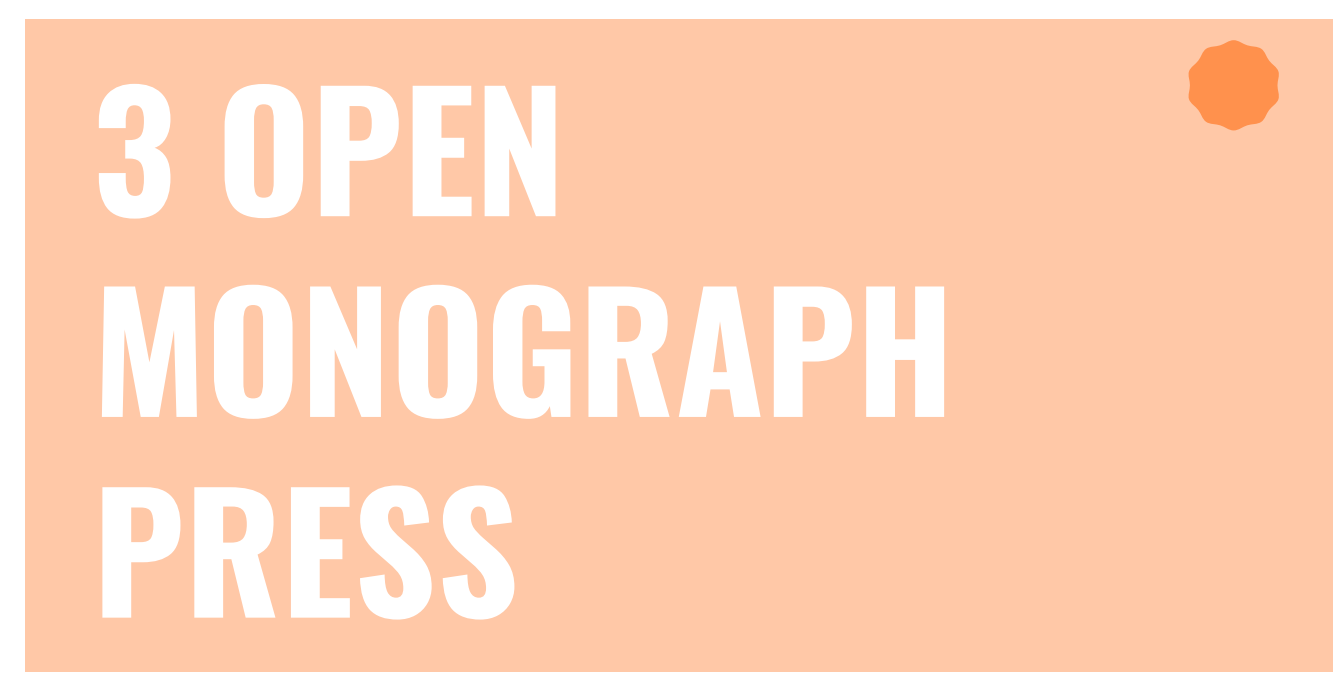

O OMP é um sistema desenvolvido em código aberto ${ }^{1}$ que permite gerenciar e acompanhar a gestão do fluxo editorial em publicações online que podem ser disponibilizadas em diferentes formatos. O software tem como finalidade proporcionar mais interação entre o autor, editor e o avaliador, garantindo que a publicação tenha qualidade e atendendo todos os critérios necessários para ser considerada um livro.

O uso do OMP por órgãos do governo pode oferecer celeridade na disponibilização da informação ao público, mantendo o histórico desde a criação até a publicação em um mesmo lugar. Essa centralização de dados facilita o acesso pelo editor para a geração de relatórios e coleta de outras informações que julgue necessárias. Assim, podemos iniciar nosso trabalho com a premissa que os ganhos que o OMP propicia em matéria de celeridade, padronização e acessibilidade vai ao encontro das lacunas nos processos editoriais encabeçados pelo governo brasileiro.

\footnotetext{
${ }^{1}$ Código aberto significa que os programas fontes (editáveis) ficam disponíveis para serem baixados e alterados se preciso, contrapondo-se aos softwares de código fechado que disponibilizam apenas os programas executáveis.
} 
Assim, apresentamos ao leitor um guia de depósito voltado para a editora da ANVISA.

O guia irá cobrir os seguintes temas: login no sistema, submissão, recebimento, designação, avaliação, editoração e publicação. Cada um desses pontos será abordado mais amplamente no próximo tópico.

\section{FLUXO}

\section{EDITORIAL}

\section{SUBMISSÃO}

A submissão é a etapa onde o

autor submete o manuscrito no

sistema. A submissão é uma etapa

simples, que consiste basicamente

no preenchimento de um

formulário dividido em cinco

etapas: preparar, enviar, catálogo

confirmação e próximos passos.

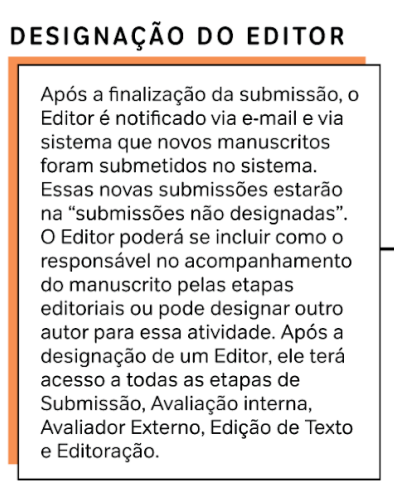

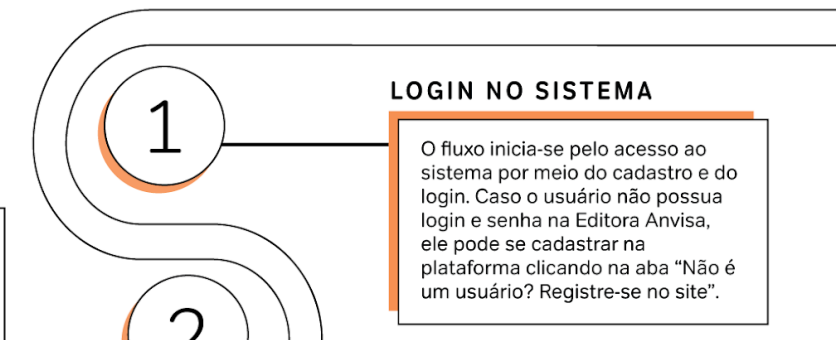

\section{RECEBIMENTO DA SUBMISSÃO}

\section{Uma vez que o autor finaliza a}

submissão do manuscrito, o Editor Geral recebe uma notificação

avisando que um novo item foi

submetido no sistema. A partir daí o

Editor pode ficar responsável ou

designar outro Editor por

acompanhar o arquivo no sistema,

assim inicia-se o fluxo editorial.

\section{AVALIAÇÃO EXTERNA \\ Na avaliação externa, é onde ocorre a avaliação pelos pares, processo em que a submissão é enviada a um especialista da area não pertencente ANVISA para avaliação, o que auxiliará no parecer do Editor responsável pela submissão.}

\section{EDITORAÇÃO}

Deve-se enviar o manuscrito que
foi revisado pelo editor de texto
para um usuário que possui a
função de designer, e
responsável pelo design gráfico
da publicação. Mesmo que a
monografia já tenha passado
pela editoração, ela não será
listada no catálogo da OMP até
que seja publicada.

Figura 1 - Infograma

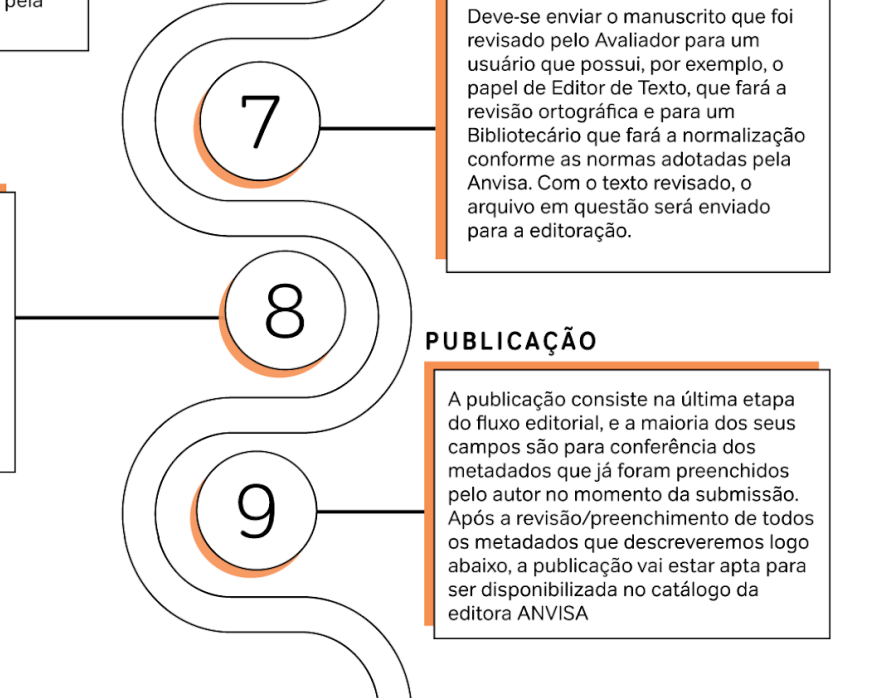

Fontes: Editora da Agência Nacional de Vigilância Sanitária (2021) 


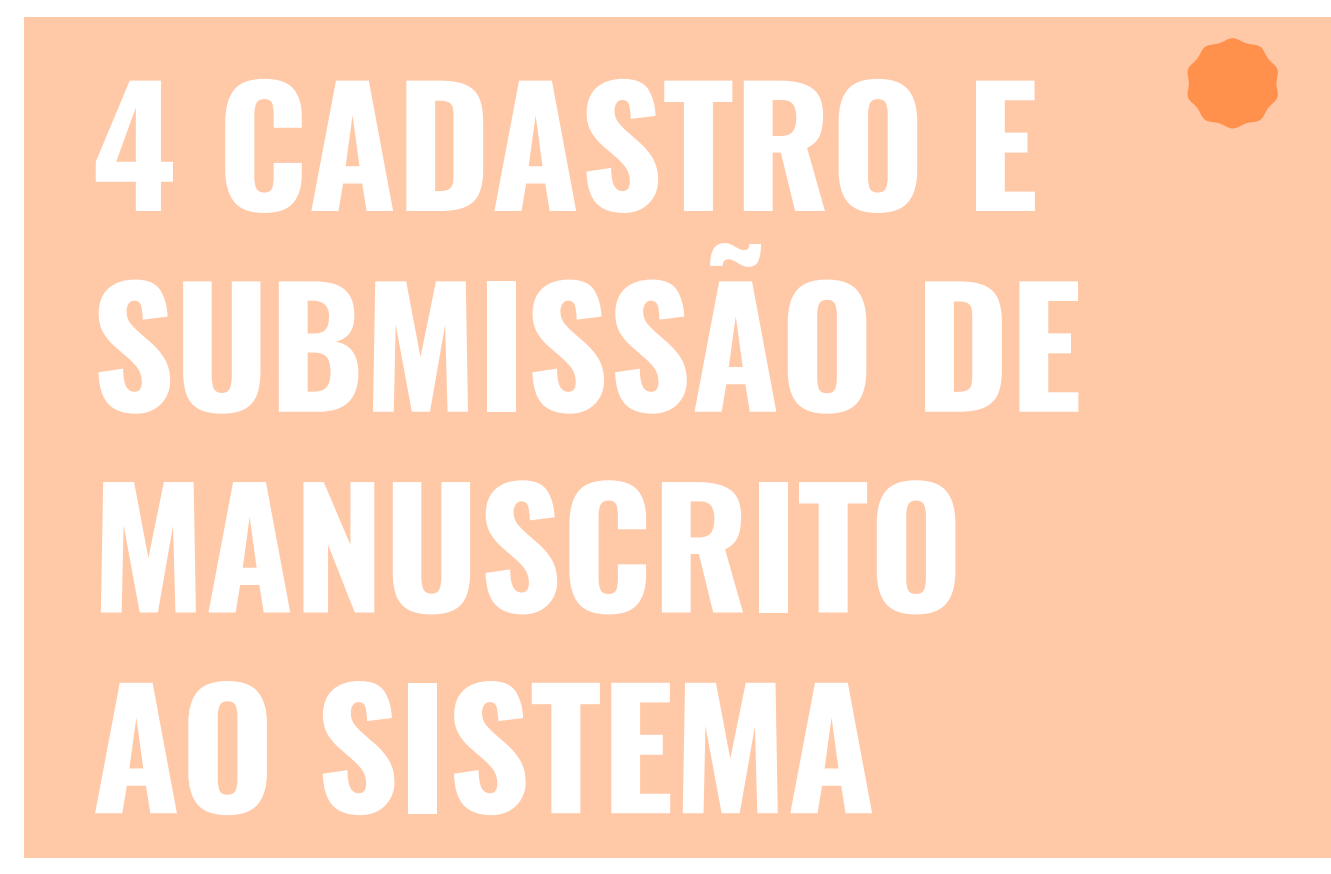

Nesta seção será apresentado o passo a passo do fluxo percorrido por um livro dentro do sistema até o momento da sua publicação.

O fluxo inicia-se pelo acesso ao sistema por meio do cadastro e do login, seguindo para a submissão e posteriormente as etapas de avaliação, edição, editoração e publicação. 


\subsection{REALIZANDO LOGHN NO OMP}

O login na Editora Anvisa² é feito pela aba "acesso", localizada no canto superior direito. Ao clicar na opção "acesso" o usuário deve informar seu login e senha.

Caso o usuário não possua login e senha na Editora Anvisa, ele pode se cadastrar na plataforma clicando na aba "Não é um usuário? Registre-se no site".

O usuário precisa estar logado no sistema para poder fazer a submissão de um Editora da Agência Nacional de Vigilância Sanitária

Catálogo Noticias Sobre -

Q Buscar
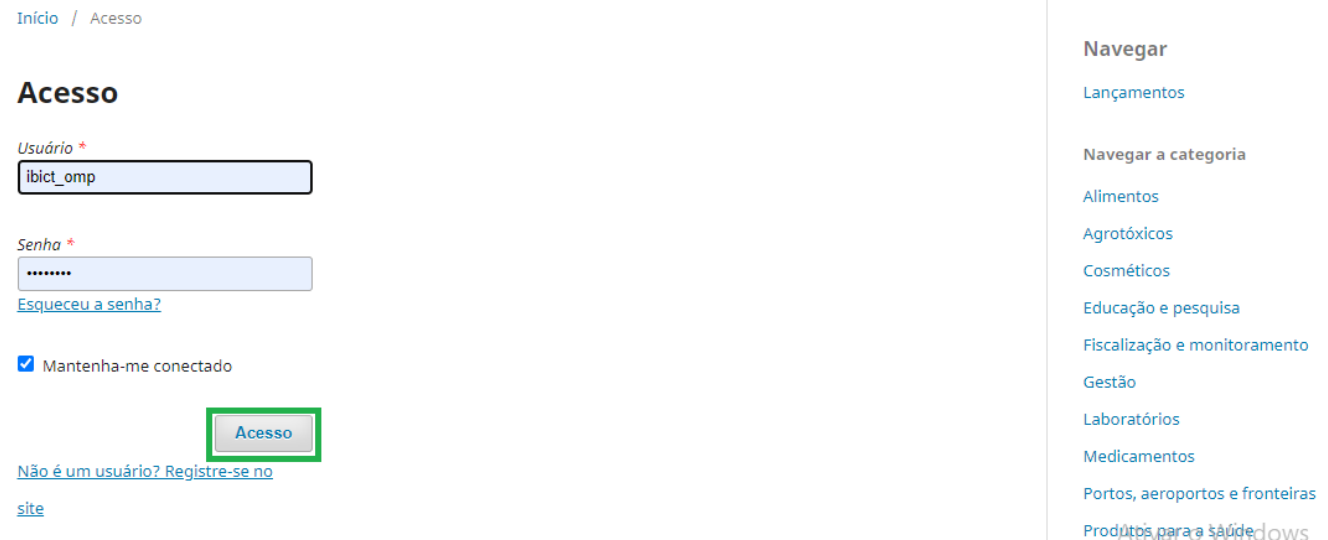

Figura 2 - Acesso a editora Anvisa.

Fontes: Editora da Agência Nacional de Vigilância Sanitária (2021)

Uma vez logado, o usuário será direcionado para o painel de controle do OMP, em que poderá navegar na função submissão e em seu perfil.

\subsection{SUBMIISSTIO}

A submissão é a etapa onde o autor submete o manuscrito no sistema. Para iniciar a submissão o autor deve clicar na opção "novo envio".

\footnotetext{
${ }^{2}$ Disponível em: http://editora.anvisa.ibict.br/index.php/edanvisa/login
} 

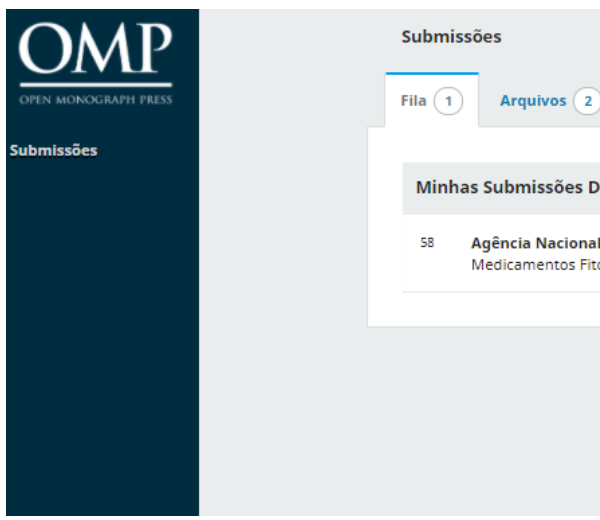

Figura 3 - Novo envio

Fonte: Editora da Agência Nacional de Vigilância Sanitária (2021)

A submissão é uma etapa simples, que consiste no preenchimento de um formulário dividido em cinco etapas: preparar, enviar, catálogo, confirmação e próximos passos. Cada uma dessas etapas será explorada abaixo.

Enviar Monografia

\begin{tabular}{lllll}
\hline 1. Preparar & 2. Enviar & 3. Catálogo & 4. Confirmação & 5. Próximos passos
\end{tabular}

Figura 4 - Etapas da submissão

Fonte: Editora da Agência Nacional de Vigilância Sanitária (2021)

\subsubsection{PREPARAR}

Abaixo descreveremos os campos da aba preparar.

\section{TIPO DE LIVRO}

O autor deve escolher entre as duas opções existentes de tipo de material: Monografia ou Volume Editado. O tipo monografia quer dizer que o autor será associado como o criador da obra em sua integralidade. No tipo Volume Editado, por sua vez, os autores serão associados aos capítulos da obra correspondentes à sua produção.

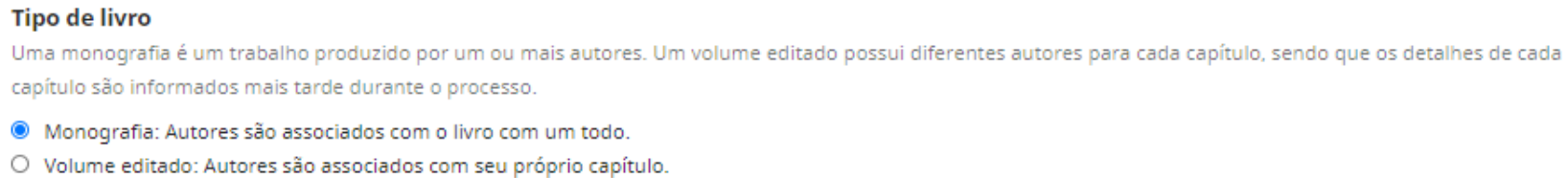

Figura 5 - Tipo de livro

Fonte: Editora da Agência Nacional de Vigilância Sanitária (2021) 


\section{SÉRIES}

A escolha da série é opcional, mas, caso o manuscrito já faça parte de uma série pré existente, ela deve ser selecionada.

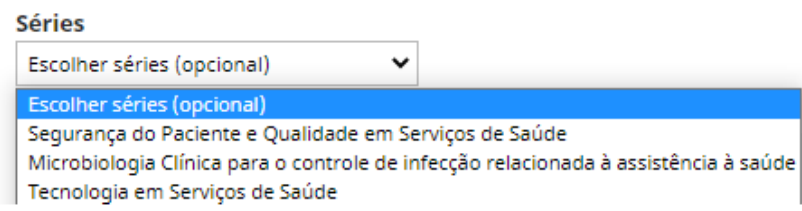

Figura 6 - Séries

Fonte: Editora da Agência Nacional de Vigilância Sanitária (2021)

\section{CATEGORIAS}

São grupos de assuntos gerais. O autor deve selecionar as categorias que melhor representam o conteúdo do manuscrito. Não tem quantidade mínima ou máxima de categorias que devem ser selecionadas, fica a critério do autor.

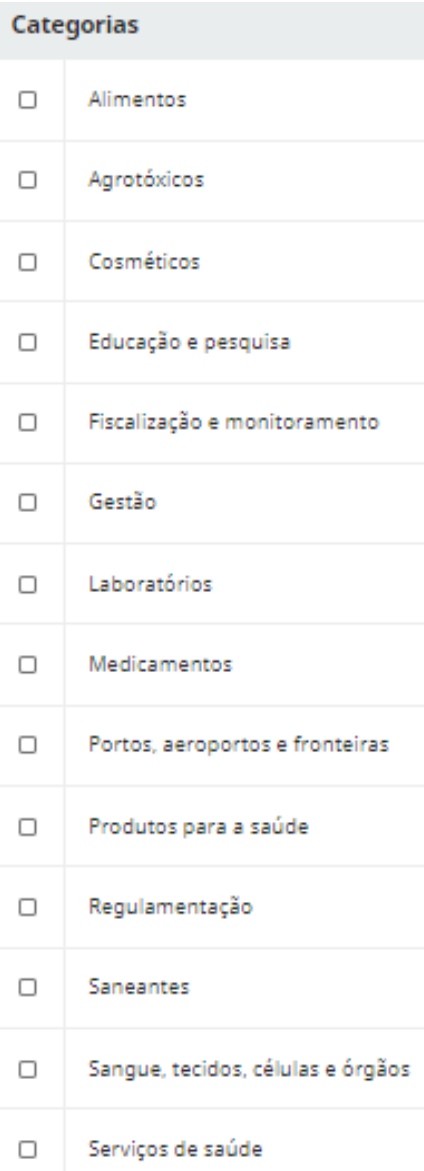

Figura 7 - Categorias

Fonte: Editora da Agência Nacional de Vigilância Sanitária (2021) 


\section{REQUISITOS PARA ENVIO DE MANUSCRITO}

São requisitos com os quais o autor tem que concordar para poder prosseguir com a submissão no sistema. Entre esses itens podem constar questões relacionadas a normas, originalidade do tema, direitos autorais, tipo de formato, entre outros.

A leitura de todos os requisitos é importante, visto que o não atendimento das normas especificadas pode acarretar na recusa do manuscrito pelo editor.

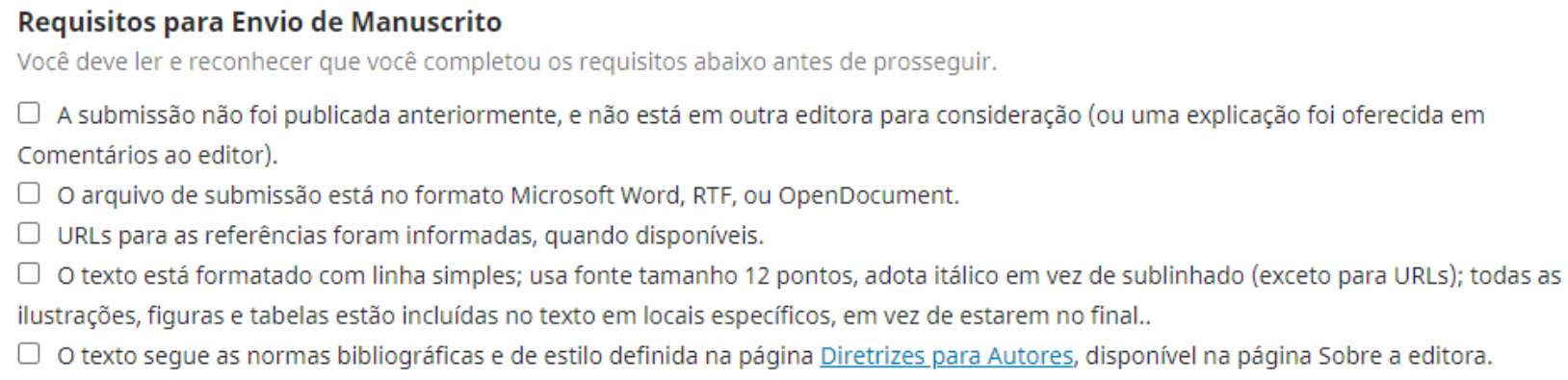

Figura 8 - Requisitos para Envio de Manuscrito

Fonte: Editora da Agência Nacional de Vigilância Sanitária (2021)

\section{ACEITAR A DECLARAÇÃO DE DIREITOS AUTORAIS}

A Editora Anvisa faz uso da Licenças Creative Commons ${ }^{3}$. Sendo assim, o autor deve declarar que respeita e cumpre os termos da declaração de direitos autorais e concordar em ter seus dados coletados e armazenados de acordo com a declaração de privacidade.

Após o preenchimento de todos os campos, o autor deve clicar em "salvar e continuar" para ir à próxima etapa da submissão.

${ }^{3}$ Disponível em: https://br.creativecommons.net/ 


\section{Aceitar a declaração de direitos autorais}

\section{A Editora Anvisa utiliza as Licenças Creative Commons.}

Sim, eu concordo em cumprir os termos da declaração de direitos autorais.

Sim, eu concordo em ter meus dados coletados e armazenados de acordo com a declaração de privacidade.

Salvar e continuar

Cancelar

Figura 9 - Aceitar a declaração de direitos autorais

Fonte: Editora da Agência Nacional de Vigilância Sanitária (2021)

\subsubsection{ENTIAR}

$\begin{array}{lllll}\text { 1. Preparar } & \text { 2. Enviar } & \text { 3. Catálogo } & \text { 4. Confirmação } & \text { 5. Próximos passos }\end{array}$

Figura 10 - Enviar arquivo

Fonte: Editora da Agência Nacional de Vigilância Sanitária (2021)

A segunda etapa, denominada enviar, consiste na transferência do(s) arquivo(s) hospedados no computador para o OMP. Primeiramente, deve-se selecionar a opção <enviar arquivo>.

Uma vez selecionada, aparecerá no monitor para o envio de arquivo(s) de submissão. $\mathrm{O}$ usuário pode optar por enviar um único arquivo em que constam todas as partes do manuscrito (texto, imagens, gráficos, quadros ou tabelas), ou enviar vários arquivos com as seções do manuscritos separadas. Ao optar pela segunda opção, o autor pode enviar, por exemplo, um arquivo com o sumário, um arquivo para cada capítulo e um último arquivo com a bibliografia. Caso, por outro lado, o autor opte por submeter a obra como um único arquivo, deve-se escolher o componente da submissão <Manuscrito de livro>.

Escolhido o componente da submissão, deve-se clicar em <Enviar arquivo>, localizar e selecionar o arquivo que está armazenado no seu computador. Após o upload do arquivo, 
deve-se clicar em "continuar". Na aba "metadados" é conferido o nome do arquivo e, caso tenha algum erro, é possível editar. Em seguida é a etapa de "finalização" que é apenas a verificação de todas as informações e, caso o documento tenha algum documento complementar, é possível realizar o upload dele.

\section{ENVIAR ARQUIVO(S) DE SUBMISSÃO}

\section{Enviar arquivo(s) de Submissão}
1. Carregar Arquivo
2. Metadados
3. Finalização

\section{Componente da Submissão *}

Manuscrito de livro

Continuar Cancelar

Figura 11 - Carregar arquivo

Fonte: Editora da Agência Nacional de Vigilância Sanitária (2021)

A opção "componente da submissão", é um campo obrigatório e oferece atualmente duas opções: o envio do manuscrito completo ou envio de capítulos. Em seguida é possível enviar o arquivo. Uma vez finalizada esta etapa, o autor vai para a aba "metadado". 
Enviar arquivo(s) de Submissão

$\begin{array}{lll}\text { 1. Carregar Arquivo } & \text { 2. Metadados } & \text { 3. Finalização }\end{array}$

guia para a qualidade em química analítica.pdf

Editar

且 pdf $\boxminus 329 \mathrm{~KB}$

Concluir

Cancelar

Figura 12 - Metadados

Fonte: Editora da Agência Nacional de Vigilância Sanitária (2021)

A segunda fase, chamada de "metadado", permite que o autor edite o nome do documento, uma vez que é dado o mesmo nome salvo no computador. Caso deseje alterar o nome/título do arquivo basta apenas clicar em <editar>. Para finalizar e passar para a próxima aba, basta clicar em <concluir>.

A alteração é opcional. Após a conclusão o autor vai para a última etapa, a "finalização".

\section{FINALIZAÇÃO}

\section{Enviar arquivo(s) de Submissão}

\section{Arquivo Adicionado}

Enviar um Novo Arquivo

Figura 13 - Finalização

Fonte: Editora da Agência Nacional de Vigilância Sanitária (2021)

A "finalização" permite ao autor adicionar documentos complementares, como, por exemplo, imagens. Se o responsável pela submissão tiver optado por enviar um único arquivo, basta clicar em <Concluir>. 
Assim como na etapa de "metadado", na "finalização" o envio de documentos complementares é opcional.

Para finalizar o Enviar arquivo(s) de Submissão, basta clicar em <Salvar e continuar>. Assim, o usuário segue para a terceira etapa da submissão, denominada catálogo.

A terceira etapa da submissão consiste basicamente na inserção dos metadados. Eles correspondem aos campos título, subtítulo, resumo, lista de coautores, capítulos, direitos e palavras-chave.

\section{TÍTULO, SUBTÍTULO E RESUMO}

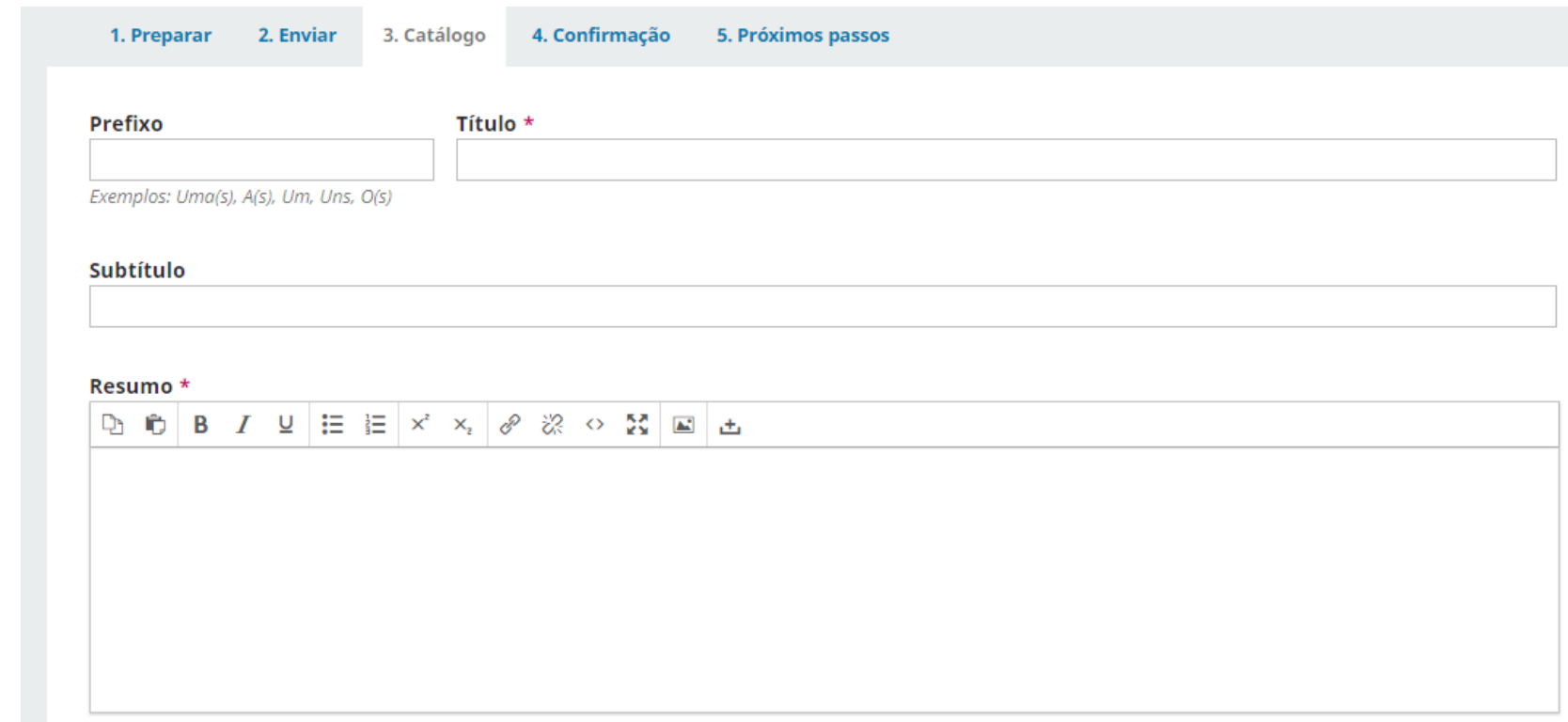

Figura 14 - Título, subtítulo e resumo

Fonte: Editora da Agência Nacional de Vigilância Sanitária (2021)

O preenchimento do título é obrigatório, enquanto o subtítulo não. O resumo também é um campo obrigatório. Caso o manuscrito tenha um resumo, ele deve ser colocado aqui. Caso não tenha, o autor precisa escrever um pequeno texto que, de forma sucinta, explique o conteúdo do material.

\section{LISTA DE COAUTORES}


Lista de Coautores

Nome
E-mail

\section{Nenhum item}

Figura 15 - Lista de Coautores

Fonte: Editora da Agência Nacional de Vigilância Sanitária (2021)

Em Lista de Coautores deve-se incluir, se existir, os demais autores da obra/do capítulo, o editor, o tradutor, o organizador, o ilustrador e o coordenador. Para incluir um desses responsáveis, basta clicar em < Incluir Coautor>, que abrirá uma nova janela para cadastrá-lo.

\section{INCLUIR COAUTOR}




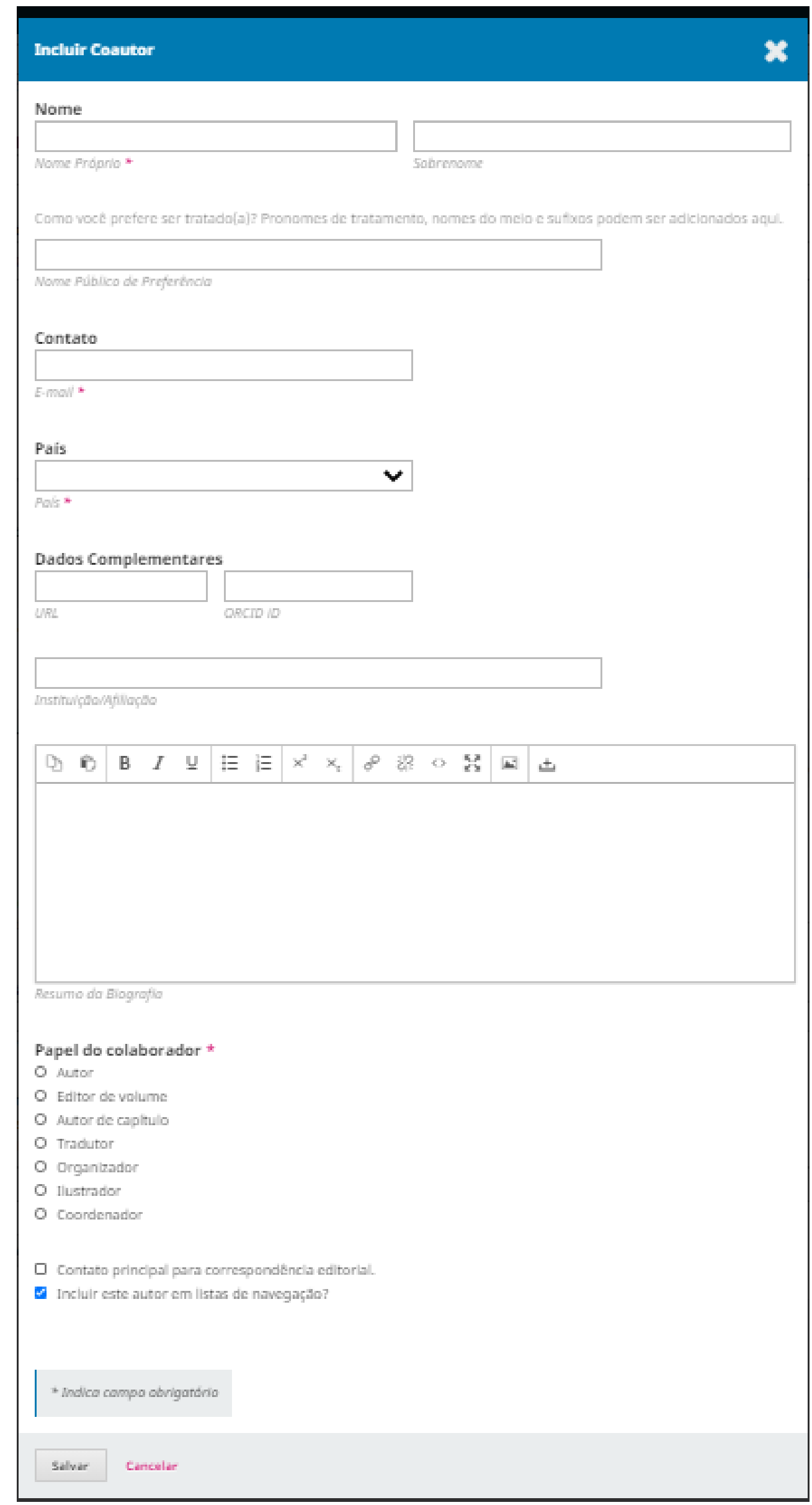

Figura 16 - Incluir Coautor

Fonte: Editora da Agência Nacional de Vigilância Sanitária (2021) 
$\mathrm{Na}$ janela para Incluir Coautor, deve-se primeiramente preencher o nome seguido do sobrenome. No campo <Nome Público de Preferência>, inserir o nome completo do colaborador (autor, editor, organizador, entre outros), seguindo de sua função entre parênteses, caso seja organizador, ilustrador ou coordenador.

\section{CONTATO}

Em contato, inserir o e-mail da autoria, caso seja necessário tirar alguma dúvida com o mesmo ou que o software Ihe envie algum passo/mudança no fluxo editorial da phatis

Neste campo, deve-se selecionar o País de nacionalidade do autor.

\section{DADOS COMPLEMENTARES}

Para preencher os dados complementares, primeiro é necessário verificar se o autor possui ORCID ${ }^{4}$. Caso o ORCID do autor seja encontrado, inserir o seu endereço eletrônico no campo <URL> e no campo <ORCID iD>.

\section{INSTITUIÇÃ̃O/AFLLIAÇÃ̃O}

Deve ser preenchido com o órgão ao qual o autor está vinculado.

\section{RESUMO DA BIOGRAFIA}

Deve conter informações sobre o autor, como a formação, titulação, interesses, linha de pesquisa, a instituição à qual ele está ligado e demais informações que o autor julgue relevantes.

${ }^{4}$ Disponível em https://orcid.org/. 


\section{PAPEL DO COLABORADOR}

Selecionar o papel que esse responsável intelectual está desempenhando na obra (autor, editor de volume, autor de capítulo, tradutor, organizador, ilustrador, coordenador) que está sendo descrita e concordar com um aceite nos termos da caixa de diálogo. Para finalizar o cadastro, clique em <salvar >.

\section{CAPITULOS}

Capítulos

Nome
E-mail

Nenhum item

Figura 17 - Capítulos

Fonte: Editora da Agência Nacional de Vigilância Sanitária (2021)

Caso o manuscrito apresente capítulos com resumos é recomendado incluir os capítulos do manuscrito. Para incluir um capítulo, basta clicar em < Incluir capítulo>, e será aberta uma nova aba para a descrição dos dados do capítulo. 
Título *

Subtítulo

Subtitulo

Resumo

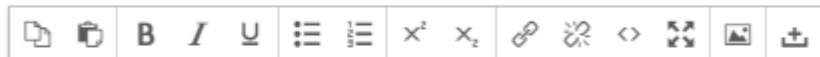

Páginas

Adicionar Colaborador

$\square \quad$ PRS autora

* Indica campo obrigatório

Salvar Cancelar

Figura 18 - Incluir capítulo

Fonte: Editora da Agência Nacional de Vigilância Sanitária (2021)

A janela incluir capítulo deve ser preenchida com os respectivos metadados de cada capítulo nos campos título, subtítulo, páginas e adicionar colaborador. TíTULO E SUBTÍTULO

O campo título e subtítulo deve ser preenchido da seguinte forma:

1. Caso o sumário seja numerado com algarismos arábicos, inserir no campo título a palavra Capítulo (primeira letra maiúscula) seguida da sua numeração arábica, como podemos observar no exemplo abaixo:

Ex: Título: Capítulo 1 (sem pontuação no final)

Subtítulo: Introdução (primeira letra maiúscula)

2. Caso o sumário seja numerado com algarismos romanos, inserir no campo título a 
palavra Capítulo (primeira letra maiúscula) seguida da sua numeração romana, como podemos observar no exemplo abaixo:

Ex: Título: Capítulo I (sem pontuação no final)

Subtítulo: Poder de polícia da ANVISA (primeira letra maiúscula)

3. Caso o sumário não seja numerado, nem com algarismos arábicos/romanos, preenche-se o campo título sem a palavra capítulo e sem numeração, como podemos observar no exemplo abaixo:

Ex: Título: Métodos de ensaios analíticos (primeira letra maiúscula)

Subtítulo: identificação e doseamento (primeira letra minúscula)

\section{RESUMO}

Recomenda-se transcrever o resumo do capítulo de forma sucinta e clara, descrevendo as principais ideias do capítulo juntamente com o seu tema central, onde a finalidade será que o usuário compreenda e identifique a ideia geral sobre o seu sentido.

\section{PÁGINA}

Campo destinado para o preenchimento da página inicial e final do capítulo, separado por um hífen (-). Caso o capítulo do livro seja de uma autoria específica, deve-se selecionar o(s) autor(es) pertencentes aos capítulos na caixa de diálogo. Finalizado o preenchimento, clique em <salvar>.

\section{DIREITOS}

Refere-se aos direitos de acesso sobre esta submissão. O preenchimento deste campo não é obrigatório, mas é recomendado. Para o preenchimento desse campo, foi criado o texto abaixo:

"Todos os direitos reservados. É permitida a reprodução parcial ou total desta obra, desde que citada a fonte e que não seja para venda ou qualquer fim comercial. A responsabilidade pelos direitos autorais de textos e imagens desta obra é da área técnica".

\section{PALAVRAS-CHAVE}


O último campo da terceira etapa é para adicionar as palavras-chave. Basta digitar cada termo/descritor e pressionar a tecla Enter. Recomenda-se inserir no mínimo três descritores e no máximo cinco, para cada manuscrito. Para passar para a próxima etapa basta clicar em < Salvar e continuar $>$.

\subsubsection{BONFIRMAGHO}

$\begin{array}{llll}\text { 1. Preparar } & \text { 2. Enviar } & \text { 3. Catálogo } & \text { 4. Confirmação }\end{array}$

Sua submissão está no sistema e pronta para ser finalizada. Você pode voltar e ajustar as informações fornecidas antes de continuar. Quando estiver pronto, clique em "Finalizar Submissão".

Finalizar Submissão

Cancelar

Figura 19 - Confirmação da submissão

Fonte: Editora da Agência Nacional de Vigilância Sanitária (2021)

A etapa Confirmação é a finalização da submissão por parte do autor. O sistema alerta que a submissão está pronta para ser finalizada e caso seja necessário, o responsável pelo processo ainda pode voltar e ajustar algum campo preenchido antes de continuar. Para prosseguir para a próxima etapa basta clicar em <Finalizar submissão>.

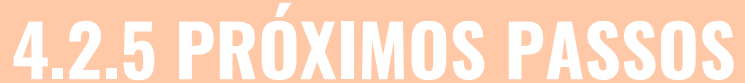

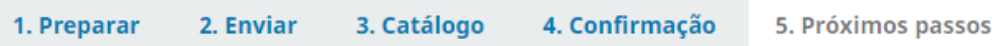

\section{Submissão completa}

Obrigado pelo seu interesse em publicar com Editora da Agência Nacional de Vigilância Sanitária.

O que acontece a seguir?

A editora foi notificada de sua submissão, bem como uma mensagem de confirmação enviada ao seu endereço de e-mail para seus registros. $\mathrm{O}$ editor entrará em contato assim que concluir sua avaliação da submissão.

Por enquanto, você pode:

- Revisar esta submissão

- Criar uma nova submissão

- Voltar para seu painel

Figura 20 - Próximos passos

Fonte: Editora da Agência Nacional de Vigilância Sanitária (2021) 
A quinta e última etapa da submissão é de natureza informativa. Ela alerta o usuário que a submissão foi finalizada e o direciona para os próximos passos do fluxo editorial. 


\section{. \\ D) 1}

Uma vez que o Autor finaliza a submissão do manuscrito, o Editor recebe uma notificação avisando que um novo item foi submetido no sistema. A partir daí este Editor pode ficar responsável ou designar outro Editor por acompanhar o arquivo no sistema. Assim inicia-se o fluxo editorial.

$\mathrm{Na}$ aba Submissão, o editor tem acesso a quatro itens, sendo eles: fila, não designados, ativos e arquivos. Cada um deles exerce uma função importante dentro do sistema.

\section{FILA}

Trata-se dos arquivos designados ao usuário logado. São visualizados somente por ele. Os editores habilitados podem designar avaliadores ou novos editores, assim como rejeitar ou aceitar a submissão.

\section{NÃO DESIGNADOS}

São arquivos que requerem algum tipo de ação por parte do editor gerente, como por exemplo a falta de designação de um revisor ou editor gerente. 


\section{ATIVOS}

São as submissões que foram enviadas e que estão em uma das quatro etapas do fluxo editorial.

\section{ARQUIVOS}

São os arquivos que já passaram pelo fluxo editorial e foram publicados ou rejeitados.

\section{MINHAS SUBMISSÕES DESIGNADAS}

$\mathrm{Na}$ opção "minhas submissões designadas", basta clicar no título da publicação designada para dar início às decisões com a submissão em questão, com objetivo de dar prosseguimento no fluxo editorial.

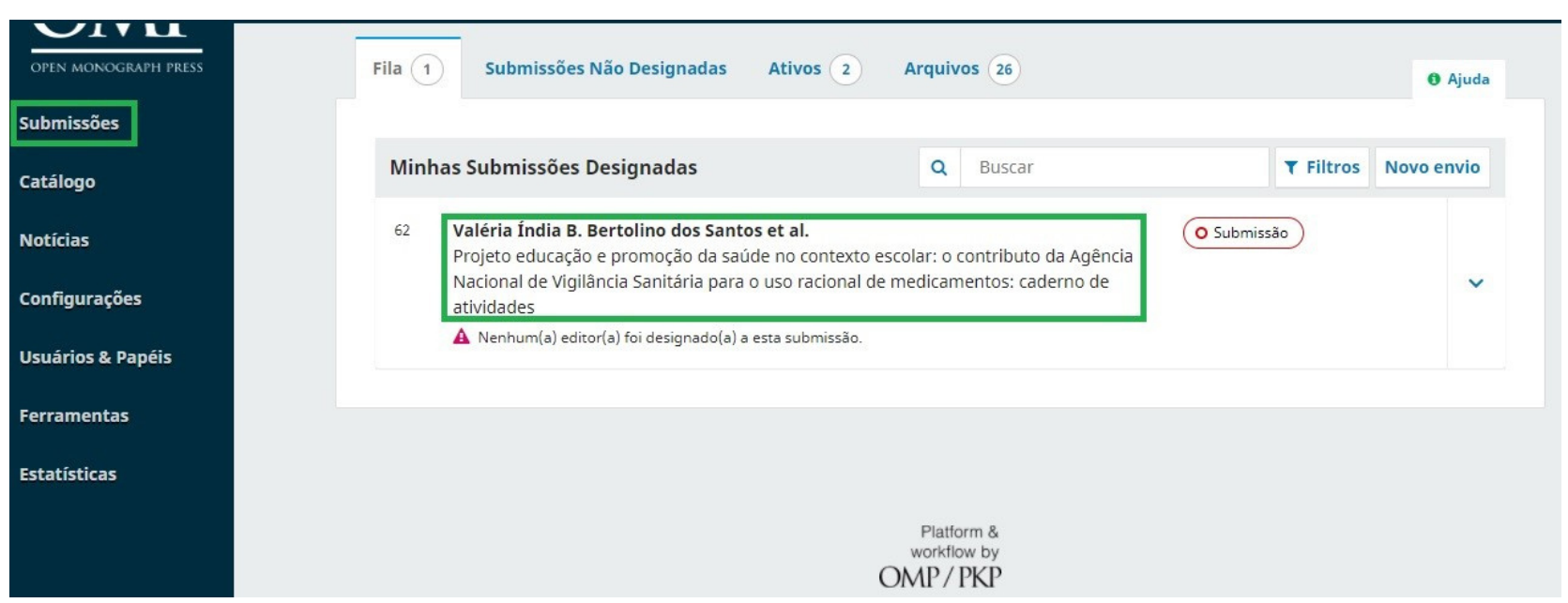

Figura 21 - Minhas Submissões Designadas

Fonte: Editora da Agência Nacional de Vigilância Sanitária (2021) 
Após a finalização da submissão, o Editor é notificado via e-mail e via sistema que novos manuscritos foram submetidos. Essas novas submissões estarão na aba "submissões não designadas". O Editor poderá se incluir como o responsável no acompanhamento do manuscrito pelas etapas editoriais ou pode designar outro autor para essa atividade. Após a designação de um Editor, ele terá acesso a todas as etapas do fluxo editorial, sendo elas a Submissão, Avaliação interna, Avaliador Externo, Edição de Texto e Editoração.

É importante que o manuscrito tenha o acompanhamento de pelo menos um Editor, caso contrário, o sistema não habilita funções como "Enviar para avaliação Interna"; Enviar para avaliação externa", "rejeitar submissão" e "Enviar para a Edição de Texto", e sem acesso a essas informações não é possível continuar o processo editorial do manuscrito. 


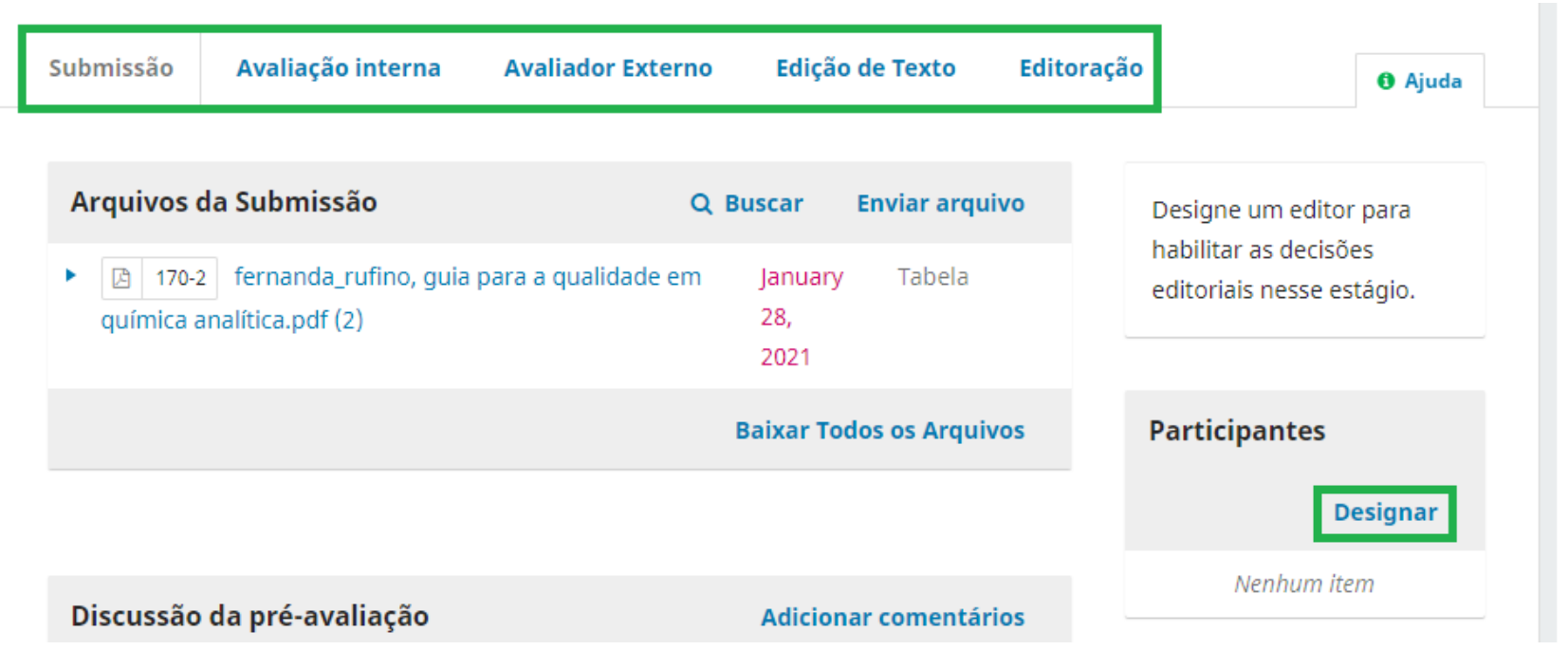

Figura 22 - Cinco etapas do fluxo editorial e designação de Editor.

Fonte: Editora da Agência Nacional de Vigilância Sanitária (2021)

\section{DESIGNAR}

$\mathrm{Na}$ tela que irá abrir para Adicionar Participante, basta realizar a busca escolhendo a função Editor geral, digitar o nome e selecionar a opção <buscar>. Assim que encontrar o usuário desejado, selecionar o mesmo e clicar em <ok>, no final da tela.

\section{Adicionar Participante}

(3) Ajuda

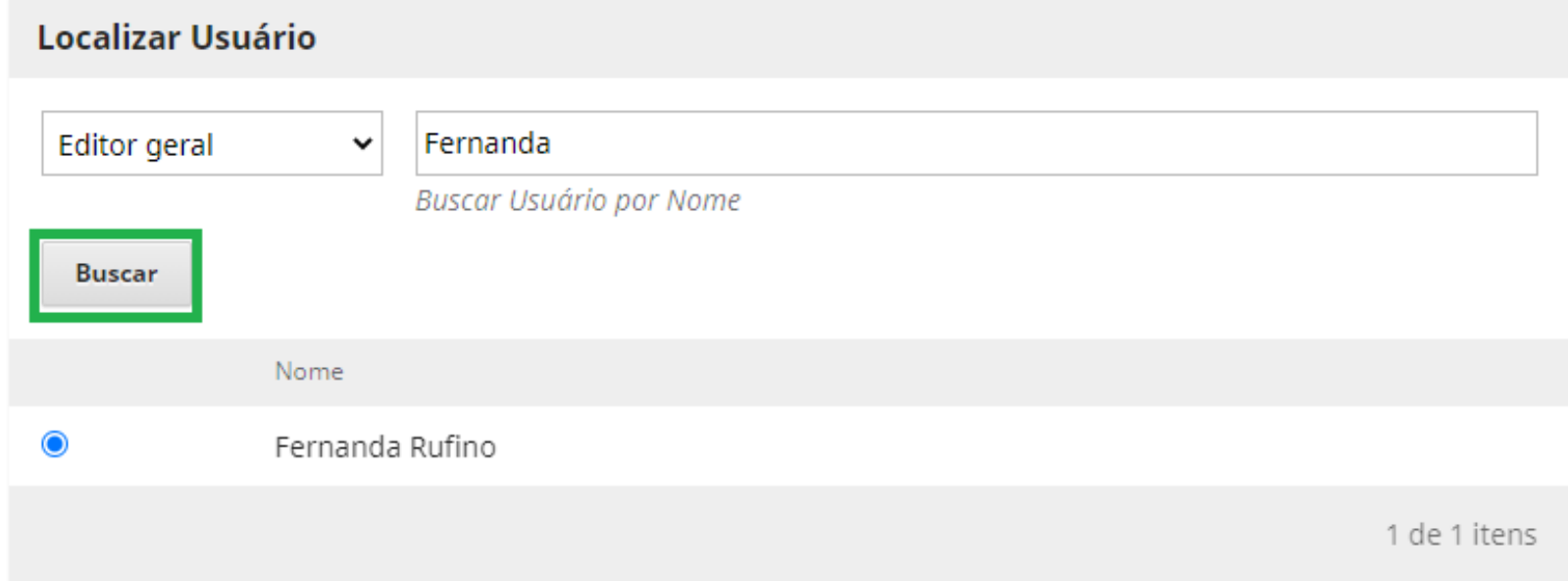

Figura 23 - Adicionar Participante

Fonte: Editora da Agência Nacional de Vigilância Sanitária (2021)

$\mathrm{Na}$ imagem abaixo, o Editor foi designado, e a partir de agora ele terá acesso a todas as etapas e funções habilitadas no sistema para ele. 


\section{Participantes}

\section{Designar}

\section{Editor geral}

- Fernanda Rufino

Figura 24 - Designar editor

Fonte: Editora da Agência Nacional de Vigilância Sanitária (2021) 


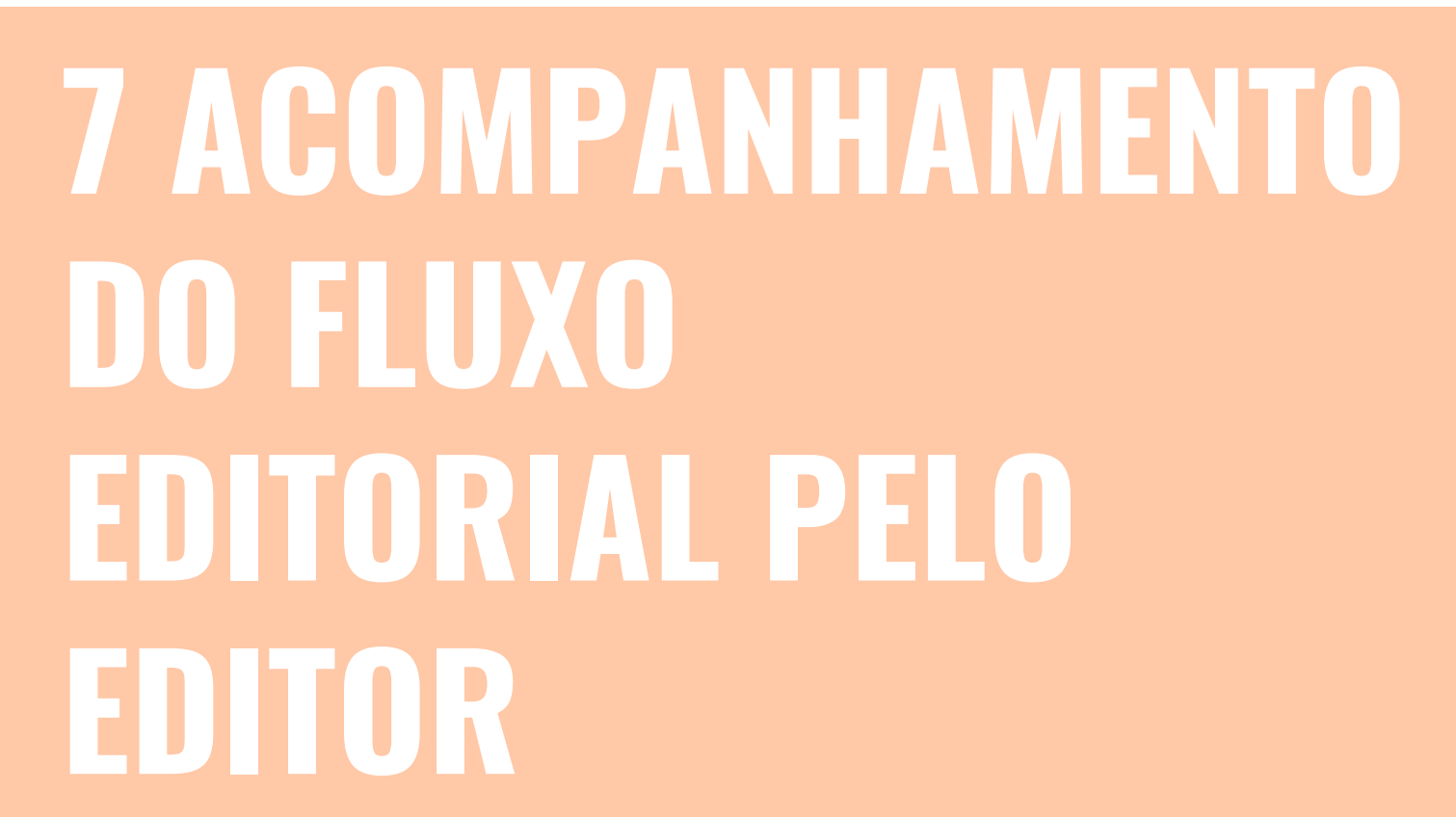

A primeira etapa do fluxo editorial que o Editor tem acesso quando clica em um manuscrito é a "submissão". Nesta fase é possível executar uma das quatro ações disponíveis nessa submissão: Enviar ao Avaliador Externo, Aceitar e Enviar para a Edição de Texto, Rejeitar Submissão e Enviar para Avaliação Interna.

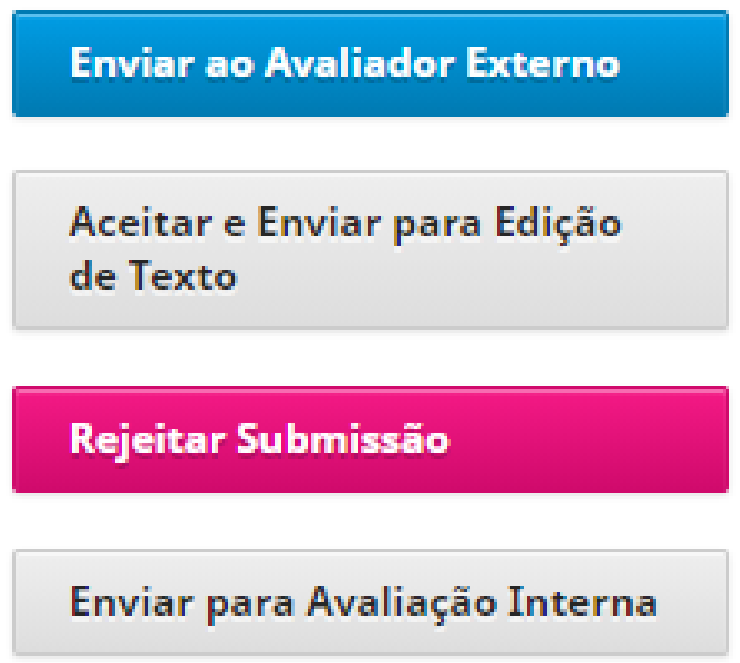

Figura 25 - Ações disponíveis na etapa de submissão

Fonte: Editora da Agência Nacional de Vigilância Sanitária (2021) 


\section{ENVIAR AO AVALIADOR EXTERNO}

A ação deve ser selecionada quando o Editor julga necessário enviar a obra a um especialista da área que não pertence à ANVISA, a fim de constatar a validação científica.

\section{ACEITAR E ENVIIAR PARA A EDIÇÃO DE TEXTO}

A obra já passou por algum tipo de avaliação anterior, como, por exemplo, já ter sido publicada, e irá pular essa etapa do fluxo editorial.

\section{REJEITAR SUBMISSÃO}

A obra será arquivada pelo Editor, pois ela não se enquadra nas Políticas Editoriais da Editora ANVISA.

\section{ENVIAR PARA AVALIAÇÃ̃O INTERNA}

O editor julga necessário enviar a publicação para um especialista da temática alocado na ANVISA, como um gerente e/ou um diretor, por exemplo, para dar o seu parecer.

Percorrendo as etapas do fluxo editorial na imagem logo abaixo, o manuscrito segue para avaliação com a opção < Enviar para Avaliação Interna>.

Fluxo de Trabalho Marketing Publicação

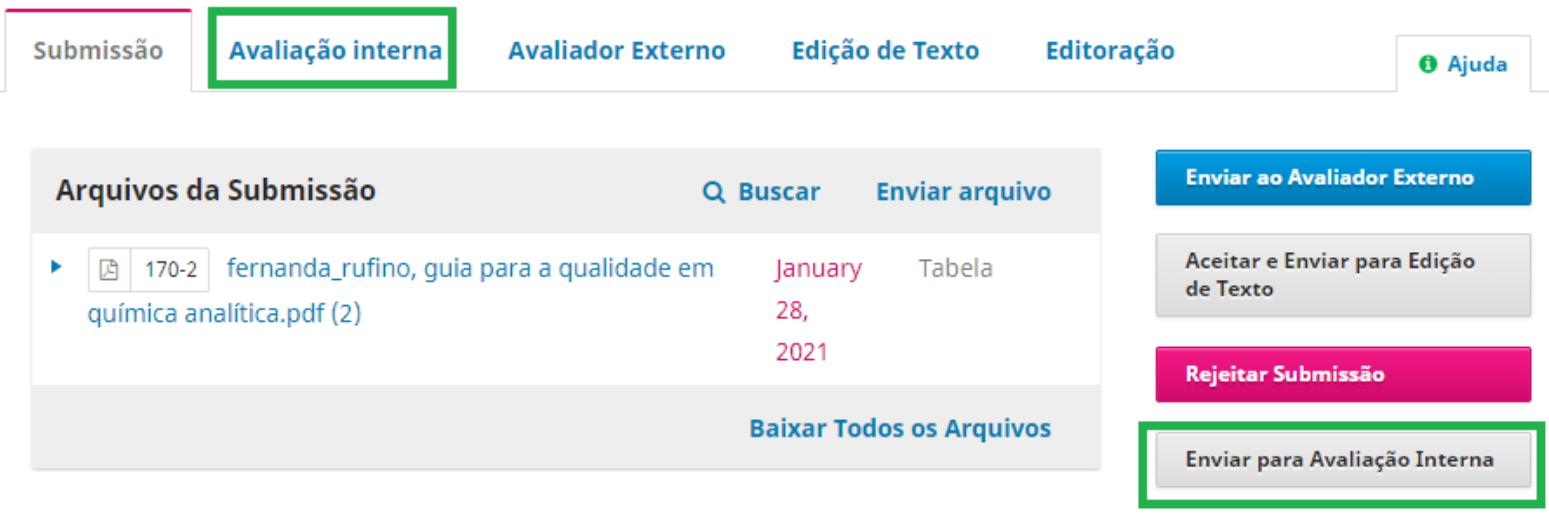

Figura 26 - Enviar para avaliação interna

Fonte: Editora da Agência Nacional de Vigilância Sanitária (2021) 


\section{AVALIADOR}

A Avaliação interna é onde ocorre a avaliação pelos pares, processo no qual a submissão é enviada a especialistas da ANVISA para avaliação. O resultado da avaliação é um passo importante em direção à publicação do material, uma vez que servirá como base para o parecer do Editor responsável pela submissão. Nessa nova aba, o primeiro passo é selecionar a opção <Adicionar Avaliador>.

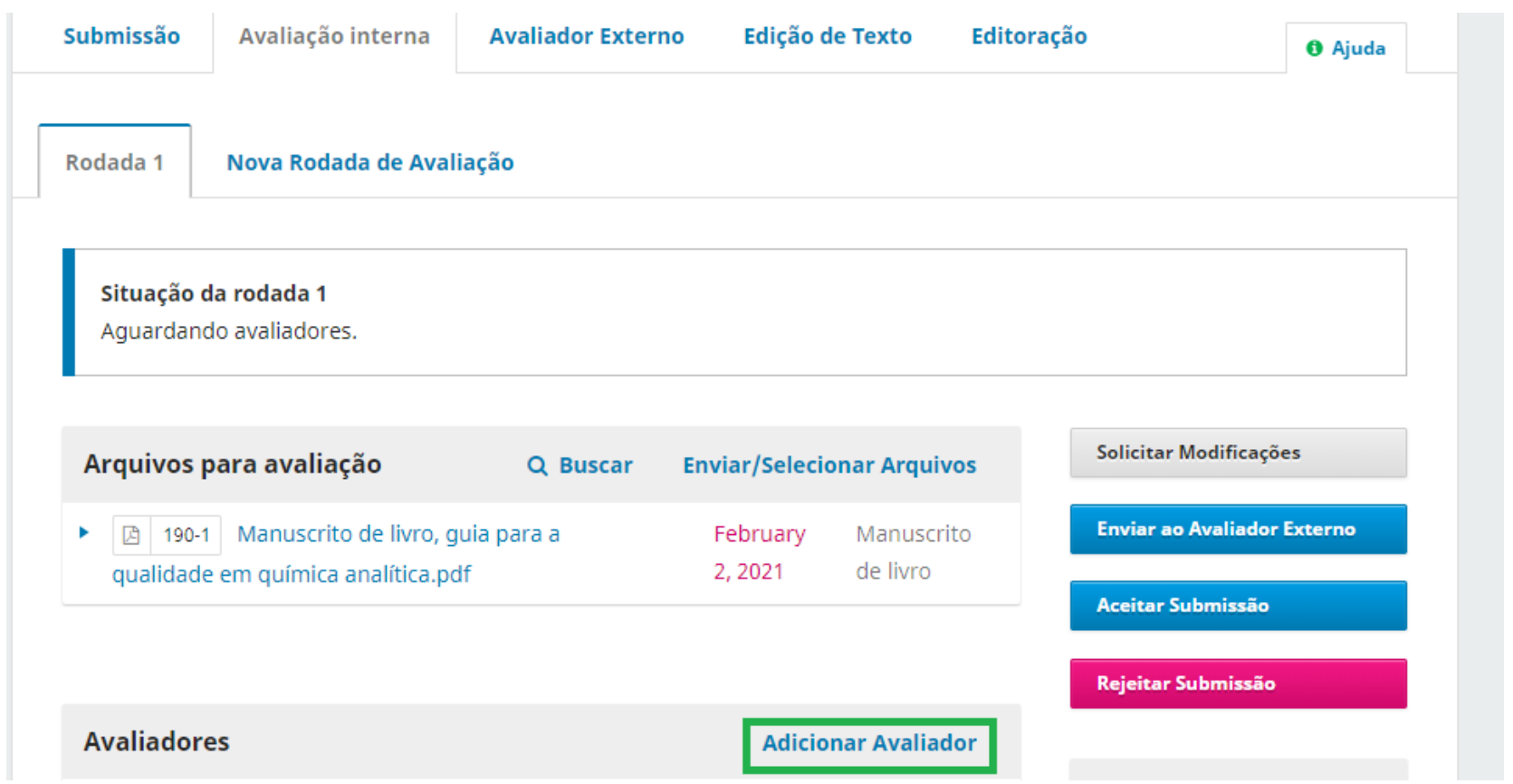

Figura 27 - Adicionar avaliador

Fonte: Editora da Agência Nacional de Vigilância Sanitária (2021)

Ao clicar em <Adicionar Avaliador> o sistema irá abrir uma nova janela com uma lista dos avaliadores cadastrados na revista. Escolhe-se, então, o avaliador desejado e posteriormente clicar em <Selecionar avaliador $>$. 
Localizar um Avaliador

\section{Fernanda Rufino}

(

(†) 2 Nunca designado

1 em andamento Priscila Rodrigues

(7) 020 dias atrás
Q Buscar

T Filtros

Figura 28 - Selecionar avaliador

Fonte: Editora da Agência Nacional de Vigilância Sanitária (2021)

\section{CRIAR NOVO AVALIADOR}

Caso o avaliador não tenha cadastro no OMP, é possível cadastrá-lo pelo "criar novo avaliador". Uma nova janela será aberta onde o Editor irá informar nome, sobrenome, usuário, e-mail, instituição/filiação.

\section{Adicionar Avaliador}

Localizar um Avaliador

\section{Fernanda Rufino}

- Esse avaliador está bloqueado porque lhe foi designado um papel que o permite ver a identidade do autor. A avaliação cega não poderá ser garantida. Gostaria de desbloquear esse avaliador mesmo assim? Desbloguear

$\mathrm{Sr}$

- Esse avaliador está bloqueado porque lhe foi designado um papel que o permite ver a identidade do autor. A avaliação cega não poderá ser garantida. Gostaria de desbloquear esse avaliador mesmo assim? Desbloguear

\section{Selecionar avaliador Criar Novo Avaliador Designar Usuário Existente}

Figura 29 - Cadastrando um novo avaliador

Fonte: Editora da Agência Nacional de Vigilância Sanitária (2021)

Na próxima tela consta um e-mail pré-configurado do OMP que será enviado para o avaliador selecionado. Pode-se ainda estipular o prazo em semanas que o avaliador tem 
para efetuar a resposta (aceitando ou recusando) ao pedido de avaliação. Por último, deve-se escolher o tipo de avaliação desejada, sendo elas: duplo-cega, cega e aberta.

\section{AVALIAĢÃO DUPLO-CEGA}

Tanto o avaliador quanto o autor da submissão desconhecem a identidade um do outro.

\section{AVALIAÇÃO CEGA/SIMPLES GEGO}

O avaliador conhece a identidade do autor da submissão, porém o autor desconhece a identidade do avaliador. Ou seja, a identidade do avaliador/revisor será anônima para o autor.

\section{AVALIAÇÃ̃O ABRIR}

Não é omitida a identificação de avaliador/autor. Para prosseguir, deve-se clicar em $<$ Adicionar Avaliador>. 
Adicionar Avaliador

Avaliador Selecionado

Femonda furfino Mualer

Email para o avaliador

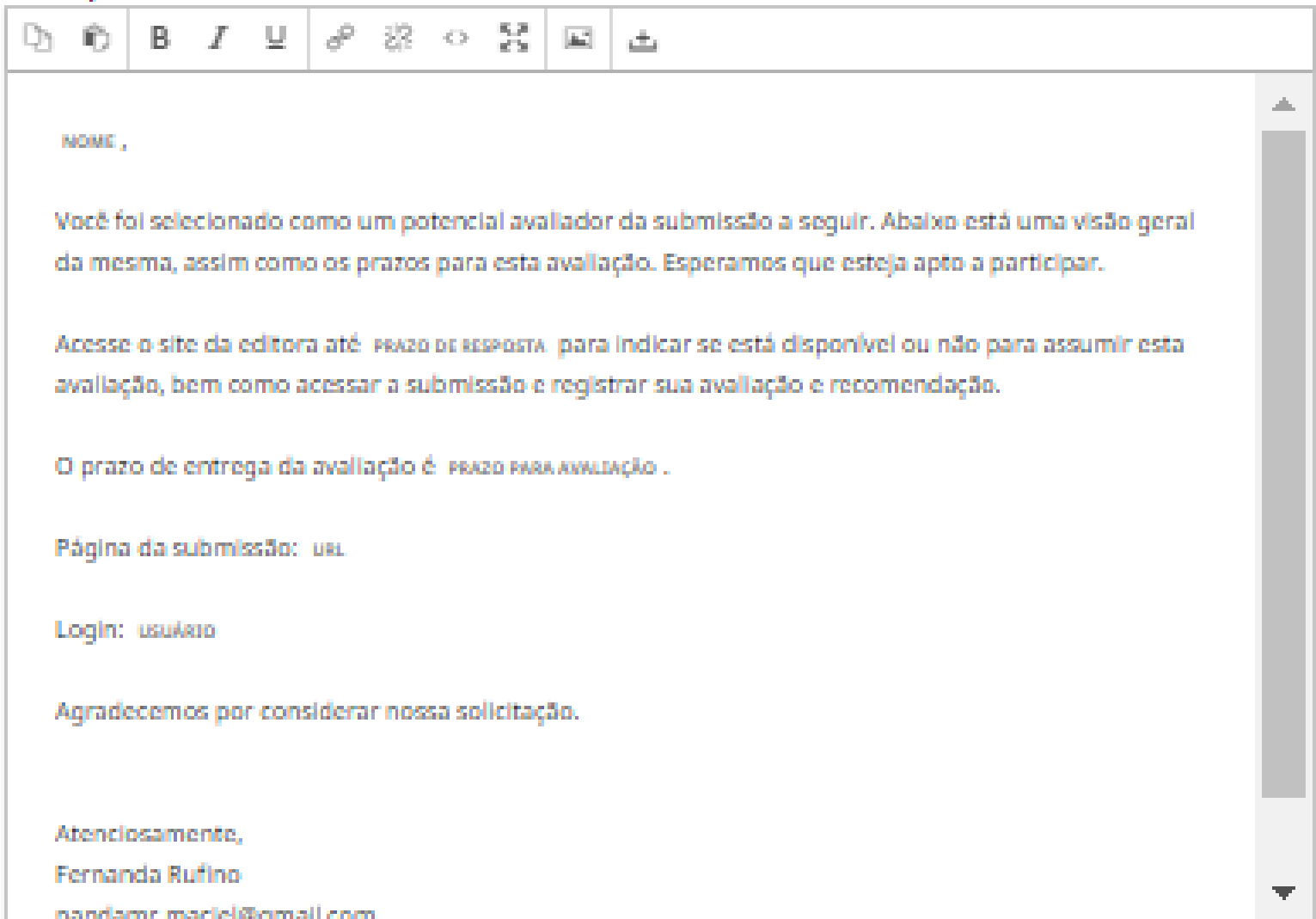

nandsmr.macielramall.scm

Nåo cnvar omall ao avalador.

\section{Datas Importantes}

$2021-03 \cdot 02$

Tipo de avaliaçāo

- Duplo-cogs

O cogs

O Abrir

Adcioner Avaliador

Centelar

Figura 30 - Adicionar avaliador

Fonte: Editora da Agência Nacional de Vigilância Sanitária (2021) 
O Avaliador adicionado será notificado via e-mail. A sua inclusão do processo editorial também estará visível na aba tarefas da sua página, por meio de uma mensagem com pedido para avaliar a submissão. Essa avaliação consiste na resposta de um formulário, dividido em quatro etapas: Requisição, Diretrizes, Download e Avaliação, Finalização.

Assim que o avaliador finalizar a avaliação atribuída a ele, ele visualiza uma mensagem agradecendo a avaliação e poderá seguir para as próximas avaliações ou sair do sistema. Uma vez finalizada a avaliação, o Avaliador não tem mais acesso ao documento e ao formulário.

O Editor é notificado que a avaliação foi finalizada. Para ver a avaliação o Editor precisa ir até "Avaliadores" e selecionar a opção < Ler Avaliação> para visualizar.

\section{Avaliadores}

- Fernanda Rufino
Adicionar Avaliador

Avaliação
Enviada

Duplo-cega

Ler

Avaliação

Figura 31 - avaliação enviada

Fonte: Editora da Agência Nacional de Vigilância Sanitária (2021)

Quando clicamos em <Ler Avaliação>, podemos ver o formulário com as respostas do Avaliador, como também classificá-lo quanto ao trabalho feito. 


\section{Fernanda Rufino}

Uma vez que a leitura da avaliação esteja completa, pressione "Confirmar" para sinalizar que o processo de avaliação pode prosseguir.

Completo em: 2021-02-13 08:22 PM

Comentários do Avaliador

Para autor e editor

Alterar os objetivos do trabalho e descrever melhor sobre a metodologia adotada.

Arquivos do avaliador

Q Buscar Enviar Arquivo

Sem arquivos

Classificação do avaliador

Avalie a qualidade da avaliação fornecida. Esta avaliação não é compartilhada com o avaliador.

O Sem avaliação

Othinthet

Onthet

Othlet

Otht

Ot

Figura 32 - Formulário com as respostas do avaliador

Fonte: Editora da Agência Nacional de Vigilância Sanitária (2021)

Conforme as sugestões dos avaliadores, o próximo passo é enviar o texto para o Autor efetuar as alterações. Para isso basta clicar em <Solicitar Modificações>, que abrirá uma mensagem de e-mail padrão. Também deve ser selecionada a opção <Incluir avaliações na mensagem> para que o Autor tenha acesso ao formulário com as sugestões do Avaliador. O Autor não consegue identificar o Avaliador pelo formulário.

Para finalizar, O Editor clica em <Gravar decisão editorial>. 


\section{Exigir Nova Rodada de Avaliação}

- Solicitar modificações ao autor.

O Solicitar modificações ao autor que estarão sujeitos a avaliação futura.

\section{Enviar e-mail}

- Enviar uma notificaçào por e-mail ao(s) autor[es]: Agência Nacional de Vigilância Sanitária

O Não enviar email ao autor

\begin{tabular}{|c|c|c|c|c|}
\hline 的 & В $I \underline{\mathrm{u}}$ & 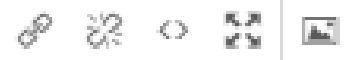 & \pm & \\
\hline \multirow{2}{*}{\multicolumn{5}{|c|}{ Agência Nacional de Vigilância Sanitária, }} \\
\hline & & & & \\
\hline \multicolumn{5}{|c|}{ A decisão editorial sobre a submissão à editora Editora para teste, "Teste Fernanda", foi tomada. } \\
\hline \multicolumn{5}{|c|}{ A decisão é: } \\
\hline \multicolumn{4}{|c|}{ Página do manuscrito: } & $\nabla$ \\
\hline
\end{tabular}

+ Incluir avaliações na mensagem

Selecione arquivos de avaliação para serem compartilhados com o(s) autor(es)

Q Buscar Enviar arquivo

- $\square$ 圆 $190-1$ Manuscrito de livro, guia para a qualidade em química analítica.pdf

February Manuscrito de

2, $2021 \quad$ livro

Figura 33 - Solicitar modificações

Fonte: Editora da Agência Nacional de Vigilância Sanitária (2021)

Assim, o Autor irá receber as considerações feitas pelo avaliador e com isso deverá enviar o texto corrigido. A versão do documento corrigida pelo Autor estará em Revisões. 


\begin{tabular}{|c|c|c|c|c|c|}
\hline \multicolumn{3}{|c|}{ Revisões } & & Q Buscar & Enviar arquivo \\
\hline - & 因 & $195-1$ & Manuscrito de capítulo, guia para a qualidade em química & February & Manuscrito de \\
\hline & anc & ica.p & & 2. 2021 & capítulo \\
\hline
\end{tabular}

Figura 34 - Revisões

Fonte: Editora da Agência Nacional de Vigilância Sanitária (2021)

Após todas as rodadas de avaliação interna/externa estarem finalizadas e o manuscrito apto para a publicação, parte-se para a próxima etapa do fluxo editorial, a Edição de Texto. Para isso basta clicar em <Aceitar Submissão>.

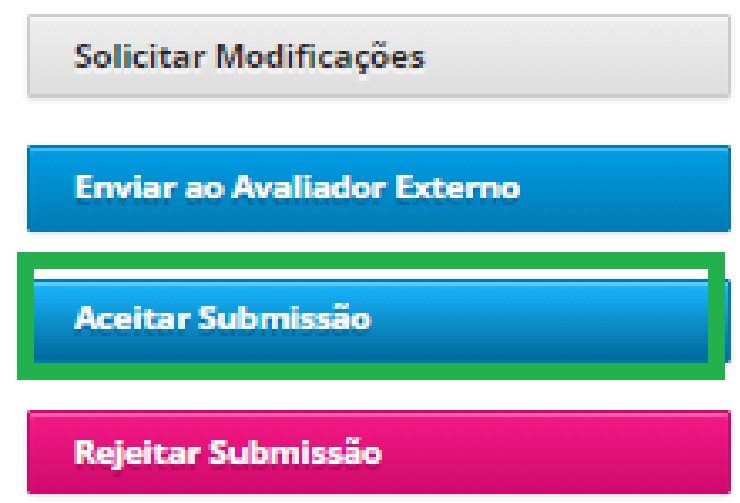

Figura 35 - Aceitar Submissão na Avaliação

Fonte: Editora da Agência Nacional de Vigilância Sanitária (2021)

Ao aceitar a submissão, abrirá uma nova janela com as informações da notificação que o autor receberá por e-mail, com um texto padrão sobre o manuscrito ter sido aceito. Ao final da janela, deve-se clicar em <Próximo: Selecionar Arquivos para Edição de Texto>. Na próxima janela automaticamente aparecerá o arquivo mais recente aquele revisado pelo avaliador e corrigido pelo autor - para ser encaminhado para o estágio de Edição de Texto. Deve ser selecionado o arquivo e clicar em $<$ Gravar decisão editorial>. Com isso, inicia-se a próxima etapa do fluxo editorial, a Edição de Texto.

\subsection{EDICHÄO DE IEKIO}

Vale ressaltar que após a avaliação pelos pares, mais especificamente nas etapas de edição e editoração, as equipes utilizam outras plataformas e ferramentas para auxílio nessas etapas.

Os passos a serem seguidos na edição de texto são similares aos da avaliação. Primeiramente, deve-se enviar o manuscrito que foi revisado pelo Avaliador para um usuário que possui, por exemplo, o papel de Editor de Texto, que fará a revisão 
ortográfica, e para um Bibliotecário, que fará a normalização conforme as normas adotadas pela ANVISA. Para isso basta ir até Participantes e selecionar a opção $<$ Designar $>$.

Enviar para Editoração

Participantes

Designar

Editor geral

- Fernanda Rufino

Figura 37 - Designar editor de texto

Fonte: Editora da Agência Nacional de Vigilância Sanitária (2021)

Ao abrir a aba Adicionar participante, em "Localizar Usuário", deve-se selecionar a opção < Editor de Texto> e clicar em <Buscar >. Na lista que aparecerá com os Editores de texto cadastrados, selecione o colaborador desejado. Posteriormente, na caixa de seleção, escolha uma mensagem predefinida e clique em $\langle\mathrm{OK}\rangle$. 


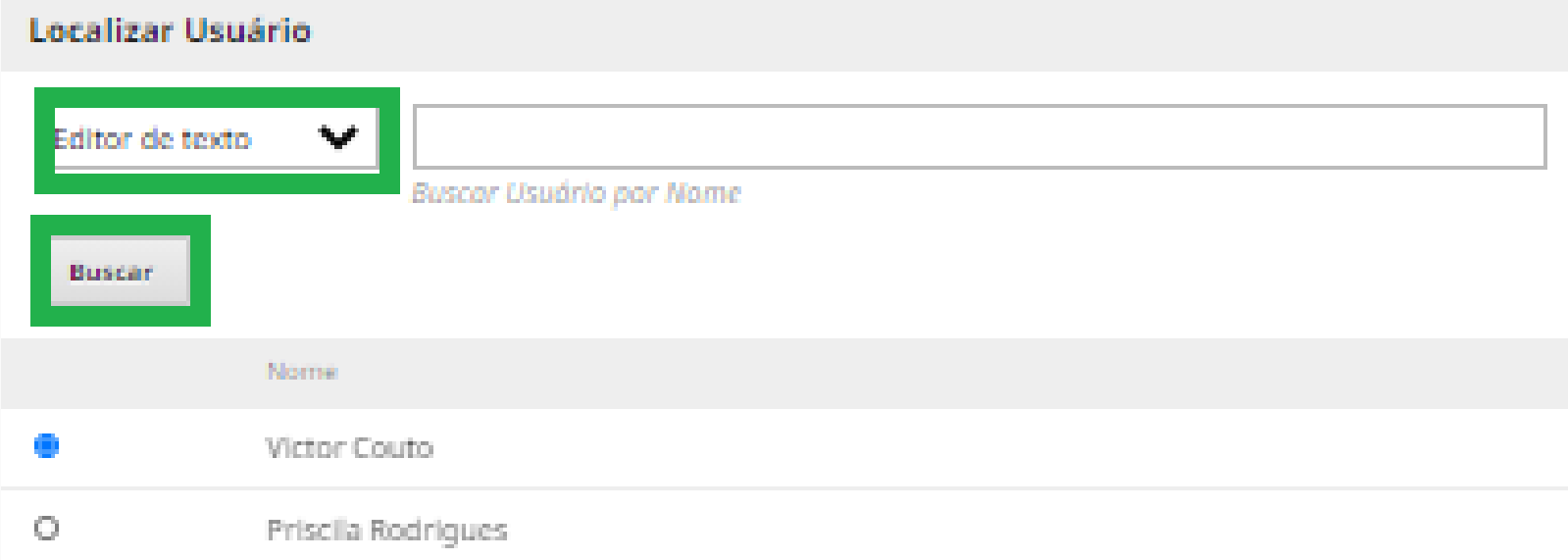

\section{Permissōes}

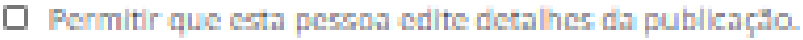

scolha uma mensagem predefinida ou preencha oformulário abaixo.

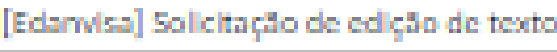

\section{Mensagem}

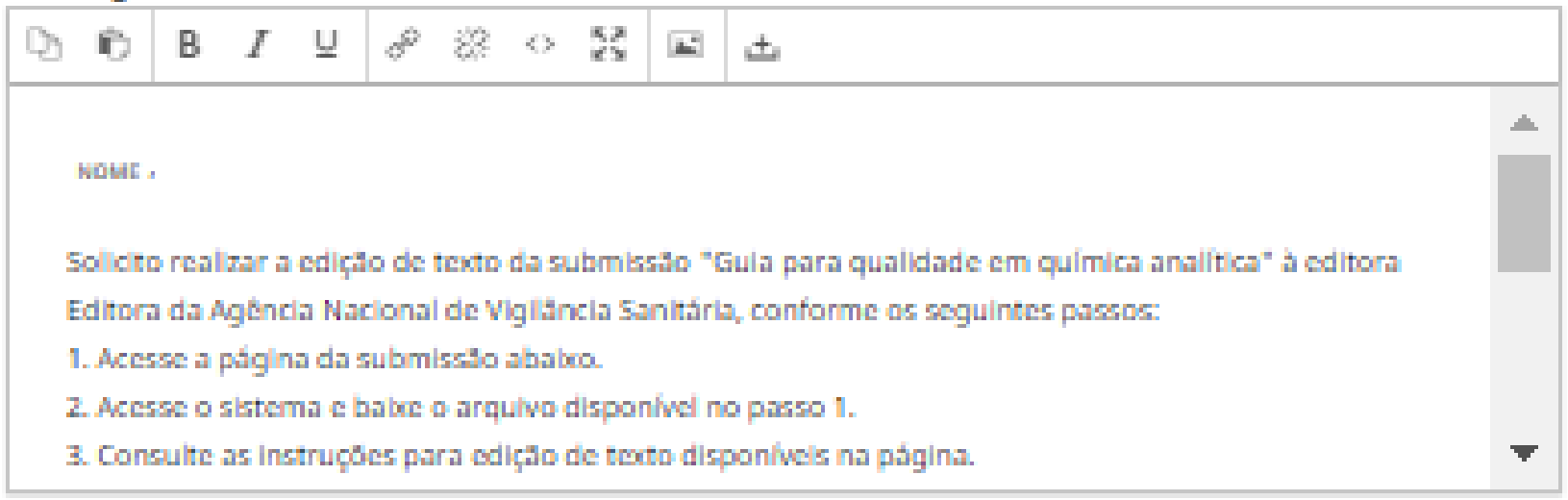

Findico campo abrigatorio

Figura 38 - Adicionar editor de texto

Fonte: Editora da Agência Nacional de Vigilância Sanitária (2021) 
O editor adicionado receberá a notificação por e-mail. Uma mensagem para revisar a versão enviada também ficará visível na aba tarefas.

Assim que o editor finalizar o processo, a publicação revisada constará no campo Texto editado, como podemos visualizar na imagem abaixo.

\begin{tabular}{|c|c|c|c|c|c|}
\hline \multicolumn{4}{|c|}{ Texto editado } & \multicolumn{2}{|c|}{ Enviar/Selecionar Arquivos } \\
\hline • & 명 & $221-1$ & revisado - guia para a qualidade em química analítica.pdf & February & Manuscrito de \\
\hline & & & & 13,2021 & livro \\
\hline
\end{tabular}

Figura 39 - Texto editado

Fonte: Editora da Agência Nacional de Vigilância Sanitária (2021)

Com o texto revisado, o arquivo em questão será enviado para a editoração. Para isto basta clicar em <Enviar para editoração>.

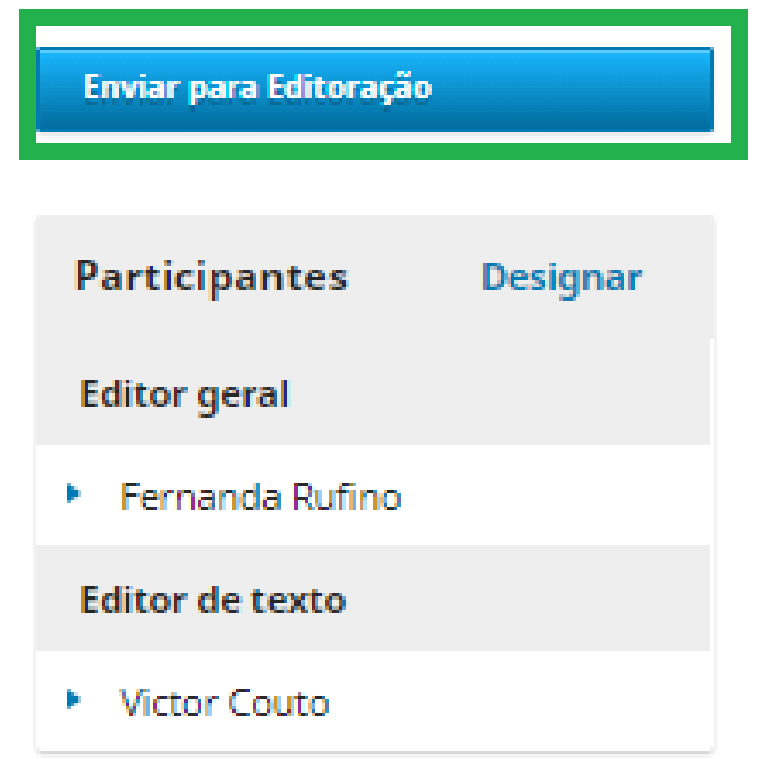

Figura 40 - Enviar para Editoração

Fonte: Editora da Agência Nacional de Vigilância Sanitária (2021)

Abrirá uma nova tela titulada Enviar para Editoração, com a opção de Enviar/Não Enviar. Ao submeter o envio o autor receberá um e-mail, alertando que o trabalho será enviado à editoração. Após escolher a opção desejada, basta clicar em <Próximo: Selecionar Arquivos para Editoração>. 


\section{Enviar e-mail}

- Enviar uma notificação por e-mail ao(s) autor(es): Agência Nacional de Vigilância Sanitária

○ Não enviar email ao autor

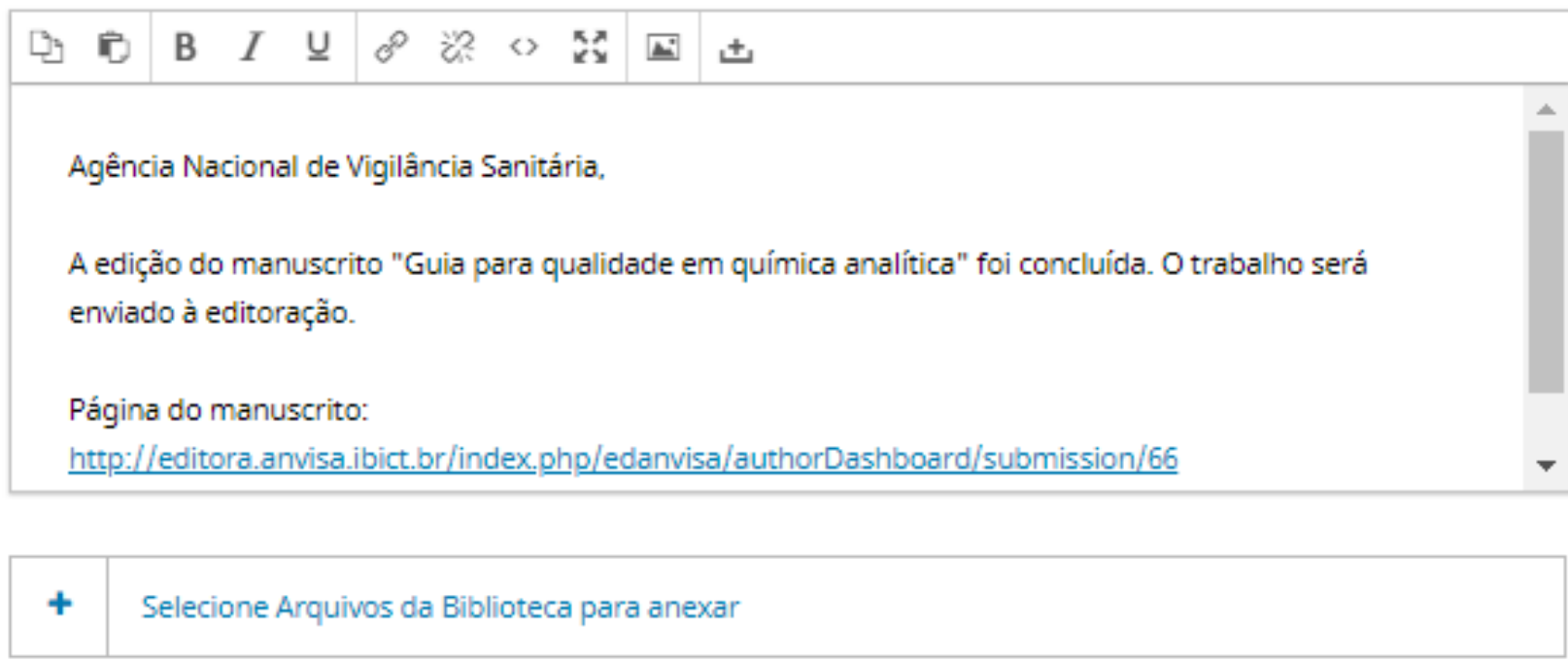

Próximo: Selecionar Arquivos para Editoração

Figura 41 - Enviar notificação por e-mail sobre a editoração

Fonte: Editora da Agência Nacional de Vigilância Sanitária (2021)

Na próxima tela, deve-se selecionar o arquivo que será editado e clicar em < Gravar decisão editorial>. Com isso, inicia-se a próxima etapa do fluxo editorial, a Editoração. 
Selecione os arquivos que gostaria de encaminhar para o estágio de Editoração.

Arquivos para edição de texto

Q Buscar

\section{Sem arquivos}

Texto editado

Q Buscar

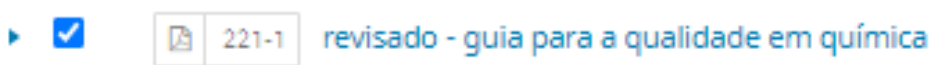
analítica.pdf

Figura 42 - Gravar decisão editorial da edição

Fonte: Editora da Agência Nacional de Vigilância Sanitária (2021)

\subsection{EDIORAGHOO}

A etapa de editoração é similar a de edição de texto. Primeiramente, deve-se enviar o manuscrito que foi revisado pelo editor de texto para um usuário que possui a função de designer (responsável pela parte gráfica da publicação). Para isso basta ir até participantes e clicar em <Designar>.

\section{Participantes}

\section{Editor geral}

\section{- Fernanda Rufino}

Figura 43 - Designar design

Fonte: Editora da Agência Nacional de Vigilância Sanitária (2021)

Ao abrir a nova tela, na caixa de seleção deve-se escolher a opção <Designer> e clicar em <Buscar>. Aparecerá uma lista com os colaboradores cadastrados nessa função e assim seleciona-se a opção pretendida. Posteriormente, na outra caixa de seleção, escolhe-se a mensagem predefinida e clica em <ok>. 


\section{Localizar Usuário}

\section{Designer}

\section{$\checkmark$}

Burcor Lhutio por Nowa

\section{E-hidr}

C

Mator Eauta

\section{Permissāes}

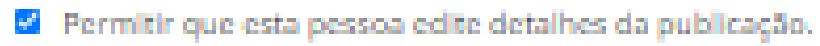

\section{Scolha uma mensagem predefinida ou preencha o formulário abaiko.}

[Edanvin! Tareta siltorlal

\section{Mensagem}

\begin{tabular}{|c|c|c|c|c|c|}
\hline 9 & 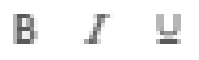 & $d z$ o 5 & H & \pm & \\
\hline \multicolumn{5}{|c|}{ cumol, } & 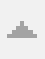 \\
\hline \multicolumn{6}{|c|}{ 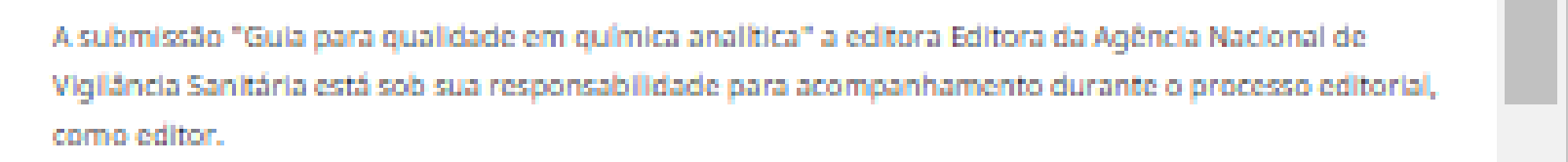 } \\
\hline Puglna & da submicita: & UA. & & & F \\
\hline
\end{tabular}

Indico compo abrigutino

Figura 44 - Adicionar Designer

Fonte: Editora da Agência Nacional de Vigilância Sanitária (2021) 
O designer adicionado receberá a notificação via e-mail e uma mensagem para revisar a versão enviada também ficará visível no seu perfil na aba tarefas.

Assim que o designer finalizar o processo, o campo Discussão da Editoração será atualizado, como pode ser observado em Última resposta.

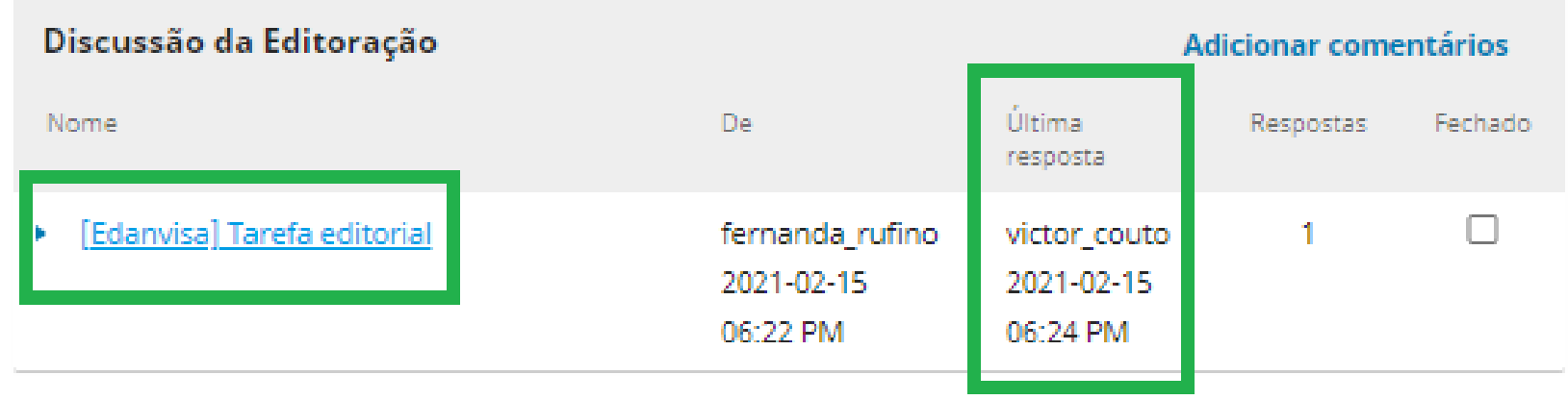

Figura 45 - Última resposta da discussão da editoração Fonte: Editora da Agência Nacional de Vigilância Sanitária (2021)

Se clicar no título da mensagem, que foi escolhida como <tarefa editorial> (figura 45) podemos visualizar a mensagem final enviada pelo Designer, como também o arquivo revisado.

- O processo de design da publicação foi concluído. Segue o arquivo abaixo

Figura 46 - arquivo revisado pelo Designer

Fonte: Editora da Agência Nacional de Vigilância Sanitária (2021)

Mesmo que a monografia já tenha passado pela editoração, ela não será listada no catálogo do OMP até que seja publicada. Para isto, basta clicar em <Agendar para Publicação>, como podemos visualizar na imagem abaixo. No próximo tópico será descrito o passo a passo da guia publicação. 


\section{Agendar para Publicação}

Participantes Designar

Editor geral

- Fernanda Rufino

Designer

- Victor Couto

Figura 47 - Agendar para publicação

Fonte: Editora da Agência Nacional de Vigilância Sanitária (2021)

\subsection{PUBLIGAGIOO}

A publicação consiste na última etapa do fluxo editorial, e a maioria dos seus campos são destinados à verificação dos metadados que já foram preenchidos pelo autor no momento da submissão. Após a revisão/preenchimento de todos os metadados que descreveremos logo abaixo, a publicação vai estar apta a ser disponibilizada no catálogo da editora ANVISA.

\subsubsection{THULO E RESUMO}

\section{PREFIXO}

Deve-se conferir o metadado prefixo. Esse campo serve para o preenchimento de artigos, caso exista algum prefixo no título da publicação. Se houver alguma modificação no fluxo editorial, deve-se atualizar. 
Prefixo

Exemplos: Uma(s), A(s), Um, Uns, O(s)

Os

Figura 48 - Prefixo

Fonte: Editora da Agência Nacional de Vigilância Sanitária (2021)

\section{TÍTULO E SUBTÍTULO}

Caso tenha ocorrido alguma alteração no título e subtítulo ou o mesmo apresentar erros de ortografia, as correções são feitas neste campo. É válido ressaltar que no final do campo não é necessário inserir pontuação, pois o OMP já faz isso de forma automática.

\section{Título}

Projeto educação e promoção da saúde no contexto escolar

Figura 49 - Título

Fonte: Editora da Agência Nacional de Vigilância Sanitária (2021)

\section{Subtítulo}

o contributo da Agência Nacional de Vigilância Sanitária para o uso racional de medicamentos

Figura 50 - Subtítulo

Fonte: Editora da Agência Nacional de Vigilância Sanitária (2021)

\section{RESUMO}

Caso tenha ocorrido alguma alteração na ideia/estrutura do texto, o campo necessitará de atualização. $O$ resumo consiste na junção das principais ideias da publicação, com a finalidade de que o usuário compreenda de forma clara e objetiva o conteúdo que será tratado naquela obra. 
B $\quad$\begin{tabular}{lll|l}
$I$ & $x^{2}$ & $x_{2}$ & 8
\end{tabular}

Este caderno é formado por textos, exercícios variados e propostas de criação e pesquisa que levam o aluno a interagir, contextualizar e vivenciar o conteúdo referente aos temas Uso Racional de Medicamentos e Propaganda de Medicamentos.

Figura 51: Resumo

Fonte: Editora da Agência Nacional de Vigilância Sanitária (2021)

Após a conferência e atualização dos campos prefixo, título, subtítulo e resumo, devese clicar em <Salvar > para prosseguir para a próxima aba da publicação.

\subsubsection{GONIRIBUTORES}

\section{LISTA DE COAUTORES}

$\mathrm{Na}$ aba contribuidores, pode-se verificar a lista de coautores e se é necessário acrescentar alguma informação sobre o autor, editor de volume, tradutor, organizador, ilustrador e coordenador já cadastrados. Para visualizar a informação de cada coautor, basta clicar na seta ao lado do nome do autor e posteriormente em Editar. 
Lista de Coautores

Nome
E-mail

nandamr.maciel@gmail.com

Agência Nacional

de Vigilância

Sanitária

Editar Excluir
Incluir Coautor

Contato

principal

Nas Listas

de

Navegação

Autor

$\nabla$

igura 52 - Lista de Coautores

Fonte: Editora da Agência Nacional de Vigilância Sanitária (2021)

Assim, abrirá a tela com os campos de identificação do colaborador cadastrado. Neste momento, caso precise, pode-se realizar alguma atualização.

\subsubsection{BAPIIULOS}

\section{CAPÍTULOS}

Em capítulos, podemos visualizar todos os capítulos registrados no momento da submissão. Assim, nesta aba, pode fazer a atualização de algum dado de um capítulo cadastrado, como, por exemplo, uma alteração na nomenclatura do mesmo. Também caso tenha sido solicitado no fluxo editorial, é possível adicionar um capítulo. Para isso basta clicar em <Incluir capítulo>, preencher a nova tela com os dados do novo capítulo e clicar em $<$ Salvar $>$.

\section{Capítulos}

Nome

- Capítulo 1
Ordenar

Incluir capítulo

\section{Nenhum item}

\section{- Capítulo 2}

\section{Nenhum item}

Figura 53 - Capítulos

Fonte: Editora da Agência Nacional de Vigilância Sanitária (2021) 
A aba Metadados reúne os campos adicionais que não estão presentes na instalação padrão e cuja inclusão pode ser sugerida por algum responsável pelo OMP de acordo com a necessidade da ANVISA. Atualmente estão presentes os campos palavraschave, tipo e ID do Editor.

\section{PALAVRAS-CHAVE}

São os descritores inseridos que melhor caracterizam a obra. Neste momento pode-se conferir os descritores, substituir ou inserir um novo termo, de acordo com a necessidade. $O$ padrão é que o manuscrito tenha de 3 a 5 palavras-chave.

\section{Palavras-chave 2}

medicamentos $\mathbf{x}$

Figura 54 - Palavras-chave

Fonte: Editora da Agência Nacional de Vigilância Sanitária (2021)

TIPO

Campo preenchido com a natureza do conteúdo principal da submissão. Se o documento enviado for um PDF, o campo deve ser preenchido como Texto, mas também pode ser um conjunto de dados.

\section{Tipo $\mathbf{3}$}

\section{Texto}

Figura 55 - Tipo

Fonte: Editora da Agência Nacional de Vigilância Sanitária (2021)

\section{ID DO EDITOR}

Campo preenchido com o ID de um site externo (não utilizado para o DOI), como, por 
exemplo, itens que foram exportados para depósito no PubMed podem incluir o ID do editor.

\section{ID do Editor $?$}

Figura 56 - ID do Editor

Fonte: Editora da Agência Nacional de Vigilância Sanitária (2021)

\subsubsection{REFERENGIAS}

\section{REFERÊNCIAS}

Neste campo são inseridas as referências que compõem o arquivo que está sendo submetido. É importante que cada uma esteja em uma nova linha para que elas possam ser apresentadas separadamente no cadastro de usuário. Após inserir todas as referências é necessário clicar em < Salvar> para prosseguir para a próxima aba.

\section{Referências}

Insira cada referência em uma nova linha para que elas possam ser extraídas e registradas separadamente.

SHINTAKU, Milton; BRITO, Ronnie Fagundes de; FERREIRA JR., Rui Seabra; BARRAVIERA, Benedito. Avaliação aberta pelos pares no âmbito da ciência aberta: revisão e reflexão. BIBLOS, [S. I.], v. 34, n. 1, p. 161-175, 2020. DOI: 10.14295/biblos.v34i1.11189. Disponivel em: https://periodicos.furg.br/biblos/article/view/11189. Acesso em: 4 fev. 2021.

SHINTAKU, Milton; SALES, Luana Farias; COSTA, Michelli (org). Tópicos sobre dados abertos para editores científicos. Botucatu, SP: ABEC, 2020. 240 p. DOI: 10.21452/978-85-93910-04-3.

Disponível em:

https://www.abecbrasil.org.br/arquivos/Topicos_dados_abertos_editores_cientificos.pdf. Acesso em: 04 fev. 2021. 


\subsection{6 |DENIFIBADORES}

Para inserir o Digital Object Identifier (DOI) basta clicar em <Atribuir > que ele será gerado de forma automática. Para prosseguir para a próxima aba, deve-se clicar em $<$ Salvar $>$.

DOI

Figura 58 - DOI

Fonte: Editora da Agência Nacional de Vigilância Sanitária (2021)

\subsubsection{FORMATOS DE PUBRIBABAOO}

A aba Formatos de publicação consiste em incluir a versão final do arquivo que foi enviado para publicação. Para tanto basta clicar em < Incluir formato de publicação>.

Formatos de publicação

Nome
Incluir formato de publicação

Concluir

Disponibilidade

\section{Nenhum item}

Figura 59 - Incluir formato de publicação

Fonte: Editora da Agência Nacional de Vigilância Sanitária (2021)

\section{INCLUIR FORMATO DE PUBLICAÇÃO}

Ao selecionar a aba "Incluir formato de publicação" uma nova janela se abrirá. Ela deve ser preenchida com algumas informações, tais como Detalhes do formato e Caminhos da URL.

\section{DETALHES DO FORMATO}

O Editor deve informar o nome do formato (PDF, XML, HTML, entre outros) e em seguida 
escolher na caixa de seleção entre as opções de formato de publicação (Digital DA, Hardback (BB) ou Paperback/softback (BC). Em seguida é preciso indicar se o arquivo estará disponível em formato físico ou em um site remoto. Por último clicar em Incluir formato de pubircaçấo

Editar

Detalhes do formato

PDF

Nome*

Formato físico

Este formato estará disponíivel em um site remoto

\section{Caminho da URL}

Um caminho opcional a ser usado na URL em vez do ID.

* Indica campo obrigatório

OK

Cancelar

Figura 60 - Aba de preenchimento do novo formato de publicação

Fonte: Editora da Agência Nacional de Vigilância Sanitária (2021)

Em seguida, clique em <Selecionar Arquivos> e na nova janela selecione o arquivo que foi aprovado na editoração. Depois basta clicar em <OK>.
Digital (DA)

Formato de publicação 
Qualquer arquivo já enviado para qualquer estágio do processo editorial pode ser adicionado aos arquivos de prova assinalando a opção 'incluir' abaixo e clicando em 'Buscar': todos os arquivos disponíveis serão listados e podem ser incluídos.

\section{Leitura de provas}

Mostrar arquivos de todos os estágios do fluxo editorial.

Editoração

$\checkmark$
园 206-1 Manuscrito de capítulo, guia para a qualidade em química analítica.pdf
Manuscrito de

capítulo

OK

Cancelar

Figura 61 - Selecionar Arquivos

Fonte: Editora da Agência Nacional de Vigilância Sanitária (2021)

Após selecionado o arquivo, deve-se habilitar as quatro caixas de diálogo. Elas são: esperando aprovação, não disponível, não aprovado e estabelecer termos. Na caixa Estabelecer termos, selecione a opção <Acesso aberto> e <Salvar>.

\section{Formatos de publicação}

Nome

- PDF Digital (DA)

Mudar Arquivo Selecionar Arquivos

- - $207-1$ Manuscrito de capítulo, guia para a qualidade em química analítica.pdf
Incluir formato de publicação

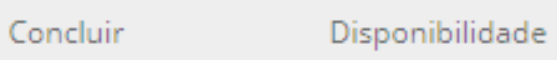

$\Xi$

Aprovado

$\Xi$ Disponível

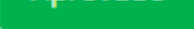

$\widetilde{\Xi}$

Aprovado
A Acesso

aberto

Figura 62 - Habilitar caixas

Fonte: Editora da Agência Nacional de Vigilância Sanitária (2021)

Na aba Formatos de publicação, também podemos adicionar o Internacional Standard Book Number (ISBN) da publicação. Para isso, basta clicar na seta que fica ao lado do nome do formato e depois clicar em < Editar>. 


\section{Formatos de publicação}

Nome

$\nabla$

PDF Digital (DA)

\section{Mudar Arquivo Selecionar Arquivos}

Editar Excluir

.

\section{7-1 Manuscrito de capítulo, guia para a} qualidade em química analítica.pdf

Figura 63 - Editar formatos de publicação

Fonte: Editora da Agência Nacional de Vigilância Sanitária (2021)
Incluir formato de publicação

Concluir

Disponibilidade

$\Xi$ Disponivel

Aprovado
$\Xi$

Aprovado
G Acesso

aberto

Abrirá uma nova tela com três abas: Editar, Identificadores e Metadados. Para adicionar o ISBN, deve-se abrir a aba Metadados.

Editar

Editar Identificadores Metadados

Figura 64 - Metadados

Fonte: Editora da Agência Nacional de Vigilância Sanitária (2021)

\section{METADADOS}

Os metadados constituem dados sobre dados. Ou seja, eles possuem a função de descrever o conjunto de dados em questão, tratando-se geralmente de uma informação inteligível por um computador. Nessa aba, podemos atribuir o DOI e o ISBN para melhor descrever a publicação.

Ao clicar em <Editar> deve-se ir até a aba <Metadados> e selecionar a caixa de verificação para que seja gerado um $\mathrm{DOI}$ automaticamente. 
DOI

10.1234/edanvisa. 66.48

O que está vendo é uma pré-visualizaçã̃o do DOI. Selecione a caixa de verificação e salve o formulário para atribuir o DOI.

Atribua o DOI a este formato de publicação

Figura 65 - DOI

Fonte: Editora da Agência Nacional de Vigilância Sanitária (2021)

\section{\#\#SUBMISSION.PUBLICATIONFORMAT.PRODUCTIDENTIFIERTYPE\#\#}

Logo abaixo do DOI, existe um metadado para incluir o ONline Information Exchange (ONIX) for Books. Trata-se de um padrão utilizado para intercâmbio de dados de publicações eletrônicas, que utiliza a linguagem XML. Para a atribuição desse dado, basta clicar em < Incluir código >.

\section{Editar}

\section{DOI}

10.1111/edteste. 58.43

O que está vendo é uma pré-visualização do DOI. Selecione a caixa de verificação e salve o formulário para atribuir o DOI.

Atribua o DOI a este formato de publicação

\#\#submission.publicationFormat.productIdentifierType\#\#

Valor do código

Tipo de código ONIX

Nenhum item

Figura 66 - Incluir código do ISBN

Fonte: Editora da Agência Nacional de Vigilância Sanitária (2021)

\section{VALOR DE CÓDIGO}

Deve-se digitar no campo o número do ISBN da publicação, sem espaços ou hífens. Vale 
lembrar que o ISBN é fornecido pela Câmara Brasileira do Livro 5 .

\section{Valor do código *}

\section{7}

Figura 67 - Valor do código

Fonte: Editora da Agência Nacional de Vigilância Sanitária (2021)

\section{TIPO DE CÓDIGO ONIX}

Escolher a opção ISBN-13(15). Essa opção se refere ao número internacional de identificação de livros que foi gerado após o ano de 2007 e que possui 13 dígitos (iniciando em 978 ou 9791-9799). Após preenchidos esses dois campos, clicar em <OK>.

\section{Tipo de código ONIX *}

ISBN-13 (15)

OK

Cancelar

\section{*Indica campo obrigatório}

Figura 68 - Tipo de código ONIX

Fonte: Editora da Agência Nacional de Vigilância Sanitária (2021)

\subsubsection{BATÁLOGO}

Nesta seção serão apresentados os metadados Data de publicação, Séries, Posição na série, Categorias, Caminho da URL, Capa. Alguns desses campos são preenchidos pelo autor no momento da submissão do manuscrito no sistema, outros são de preenchimento do Editor.

${ }^{5}$ Disponível em: $\underline{\text { https://servicos.cbl.org.br/isbn/. }}$ 


\section{DATA DE PUBLICAÇÃO}

No campo data de publicação é informado o Ano, Mês e Dia da publicação da obra no sistema. Esse preenchimento é feito de forma automática pelo OMP quando o documento é publicado.

\section{Data de Publicação}

Figura 69 - Data de publicação

Fonte: Editora da Agência Nacional de Vigilância Sanitária (2021)

\section{SÉRIES}

Caso o documento faça parte de alguma série e o Autor não a tenha especificado isso até então, o Editor deve selecionar a série em que a obra faz parte na caixa de informações.

\section{Séries}

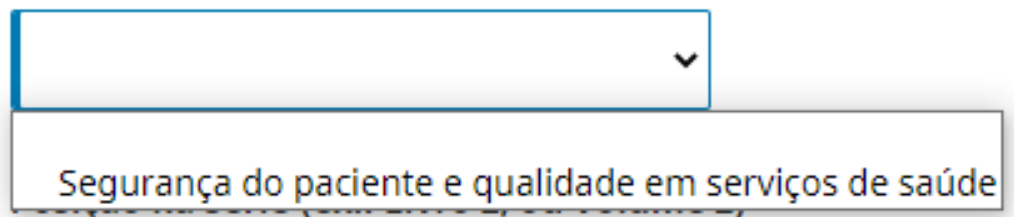

Figura 70 - Séries

Fonte: Editora da Agência Nacional de Vigilância Sanitária (2021)

\section{POSIÇÃO NA SÉRIE}

Este campo é um complemento do campo descrito acima. Caso uma série tenha sido selecionada, neste campo é descrita qual a posição em que ele se encontra dentro da série. 


\section{Posição na série (ex.: Livro 2, ou Volume 2)}

\section{Exemplos: Livro 2, Volume 2}

Caderno 2

Figura 71 - Posição na série

Fonte: Editora da Agência Nacional de Vigilância Sanitária (2021)

\section{CATEGORIAS}

O Editor deve verificar se os temas selecionados ou não pelo autor condizem com o conteúdo da obra. Este campo é uma espécie de classificação das publicações no OMP.

\section{Categorias}

Medicamentos

Figura 72 - Categorias

Fonte: Editora da Agência Nacional de Vigilância Sanitária (2021)

\section{CAMINHO DA URL}

Todo site ou portal disponível na internet tem um URL, ou endereço Web. Como o OMP pode abrigar muitas editoras em uma mesma instalação, cada editora precisa ter a sua identificação na URL, que se expressa na última parte do endereço. Por exemplo, se a editora vier a se chamar Anvisa Press, pode-se colocar neste campo anvisapress ou anvisa_press, de modo que a url completa corresponderia a http://........../anvisapress ou http://........../anvisa_press.

\section{Caminho da URL}

Um caminho opcional a ser usado na URL em vez do ID.

Figura 73 - Caminho da URL

Fonte: Editora da Agência Nacional de Vigilância Sanitária (2021)

O Caminho da URL é um campo opcional, mas nem por isso menos importante. Caso o usuário não informe o valor correto, o sistema vai identificar a editora pelo número interno, o que pode dificultar a relação entre a URL e a editora. Uma das vantagens de escolher o valor é a possibilidade de usar uma sigla ou um nome mais curto como caminho 
da URL.

\section{CAPA}

Este campo é designado ao envio do arquivo da capa da publicação, o qual ficará disponível no catálogo do OMP para melhor identificação e maior facilidade de interação do usuário com o sistema. Para incluir a capa, basta clicar em <Enviar arquivo>e fazer a seleção do documento no computador. Após o preenchimento de todos os campos da aba, clicar em <Salvar $>$.

\section{Capa}

Enviar arquivo

\subsubsection{PERMISSAO E DIYULGAGIO}

Nesta seção serão apresentados os metadados Detentor do Copyright, Ano do Copyright, e a URL da licença. São os metadados que vão informar sobre os direitos autorais da publicação.

\section{DETENTOR DO COPYRIGHT}

Este campo não necessita ser preenchido, pois o sistema automaticamente insere a Editora da Agência Nacional de Vigilância Sanitária como detentora dos direitos autorais. 


\section{Detentor do Copyright}

Os direitos autorais serão atribuídos automaticamente a Editora da Agência Nacional de Vigilância Sanitária quando publicados.

\section{Sobrepor}

Figura 75 - Detentor do Copyright

Fonte: Editora da Agência Nacional de Vigilância Sanitária (2021)

\section{ANO DO COPYRIGHT}

Este campo não necessita ser preenchido, pois o sistema automaticamente insere $o$ ano dos direitos autorais com base na data de publicação.

\section{Ano do Copyright}

O ano dos direitos autorais será definido automaticamente com base na data de publicação.

\section{Sobrepor}

Figura 76 - Ano do Copyright

Fonte: Editora da Agência Nacional de Vigilância Sanitária (2021)

\section{URL DA LICENÇA}

Este campo não necessita ser preenchido pois o sistema automaticamente define a licença 4.0 da Creative Commons $^{6}$ (CC) quando publicado. Caso seja necessário alterar o tipo de licença, basta clicar em <Sobrepor> e inserir o link da licença desejada na caixa de textos. Os tipos de licença, com suas respectivas explicações e links, encontram-se disponíveis no site da CC.

\section{Ano do Copyright}

$\mathrm{O}$ ano dos direitos autorais será definido automaticamente com base na data de publicação.

\section{Sobrepor}

Figura 77 - URL da licença

Fonte: Editora da Agência Nacional de Vigilância Sanitária (2021)

${ }^{6}$ Disponível em https://creativecommons.org/. 


\section{PUBLICAR}

Após serem preenchidas todas as abas e campos descritos, devese clicar em <Publicar> no canto superior direito da tela.

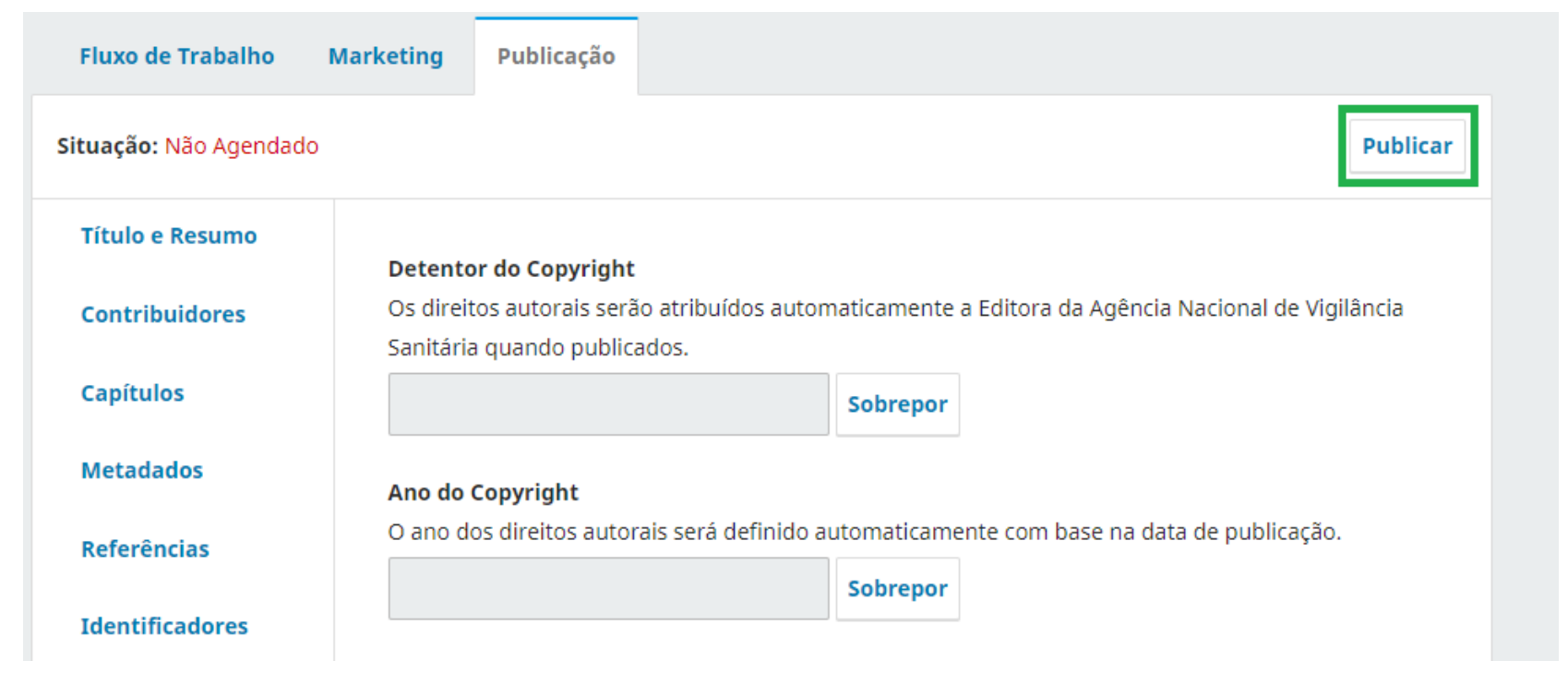

Figura 78 - Publicar

Fonte: Editora da Agência Nacional de Vigilância Sanitária (2021) 
Ao se debruçar sobre as etapas do processo editorial e descortinar a multiplicidade de caminhos que um trabalho pode percorrer desde a submissão até a publicação, este guia também fala para o leitor sobre a importância das editoras. Ora, não há dúvidas que elas (as editoras) cumprem um papel decisivo no processo de publicação de uma obra, visto que são as responsáveis pela execução do processo editorial, além da divulgação e de publicação do livro em formato digital e/ou físico. Vale lembrar que, além dessas etapas, a editora cuida dos detalhes da obra, ou seja, de tudo que esteja ligado à caracterização de um livro, como ISBN, ficha catalográfica, código de barras, entre outros.

À medida em que passamos a investigar a natureza da práxis de uma editora progressivamente nos aproximamos da constatação de que em seu guarda chuva estão contidos todos os detalhes necessários para a publicação de obras em conformidade com as regras estabelecidas. Essa descoberta diz respeito não somente à complexidade do trabalho realizado dentro das editoras, mas à sua importância dentro dos órgãos governamentais. Ao centralizar decisões e estabelecer normas, as editoras garantem que o conhecimento produzido nas instituições brasileiras seja, de fato, socializado, e que não se perca dentro do próprio Estado.

Dentro dessa perspectiva, a Editora da ANVISA assume o propósito de garantir às publicações de autoria da agência não somente adequação às normas internacionais, mas economia de tempo e custos. Por meio de um acompanhamento do fluxo editorial que 
preza pela excelência do conteúdo e pelo domínio das ferramentas necessárias para que os livros tenham reconhecimento em nível nacional e internacional, não resta dúvidas que a Agência Nacional se beneficiaria da implementação de uma editora.

Com a finalidade de atender aos objetivos de uma hipotética Editora ANVISA, o projeto firmado entre a Agência e o lbict visou a implementação de uma plataforma OMP, juntamente com um guia, que apresenta o passo a passo das etapas do fluxo editorial de um manuscrito. Da mesma forma, o guia oferece apoio ao usuário para o preenchimento correto dos metadados.

Assim, este guia preza pela qualidade das obras publicadas e pela recuperação mais rica das informações que as descrevem. Acreditamos, também, que o Guia para a editora da Anvisa funciona como um verdadeiro mediador entre o software e o usuário, e que eventualmente possibilite o Editor a desenvolver uma visão mais ampla das possibilidades do OMP.

Resumidamente, o Guia para a editora da ANVISA irá apoiar o Editor nas decisões dentro do sistema e auxiliará os demais participantes na execução das atividades atribuídas a eles. O guia não pretendeu esgotar todos os assuntos pertinente ao uso do OMP, mas destacar pontos nevrálgicos para a execução de um trabalho ágil e valoroso.

Quem sabe após esta experiência outros órgãos governamentais reivindiquem para si editoras e, uma vez que o fizerem, o caminho a percorrer se torne cada vez mais acessível, uma vez que a ANVISA já pavimentou a estrada. Quem sabe, também, o trabalho do lbict dentro do órgão represente o primeiro passo em direção a um novo modo de pensar o processo editorial e a sua importância para o Estado. Resta-nos, por hora, fazer tudo ao nosso alcance para garantir que a experiência com o OMP solucione muitos dos problemas enfrentados pela Agência e que essa ferramenta integrada descortine novas possibilidades. 


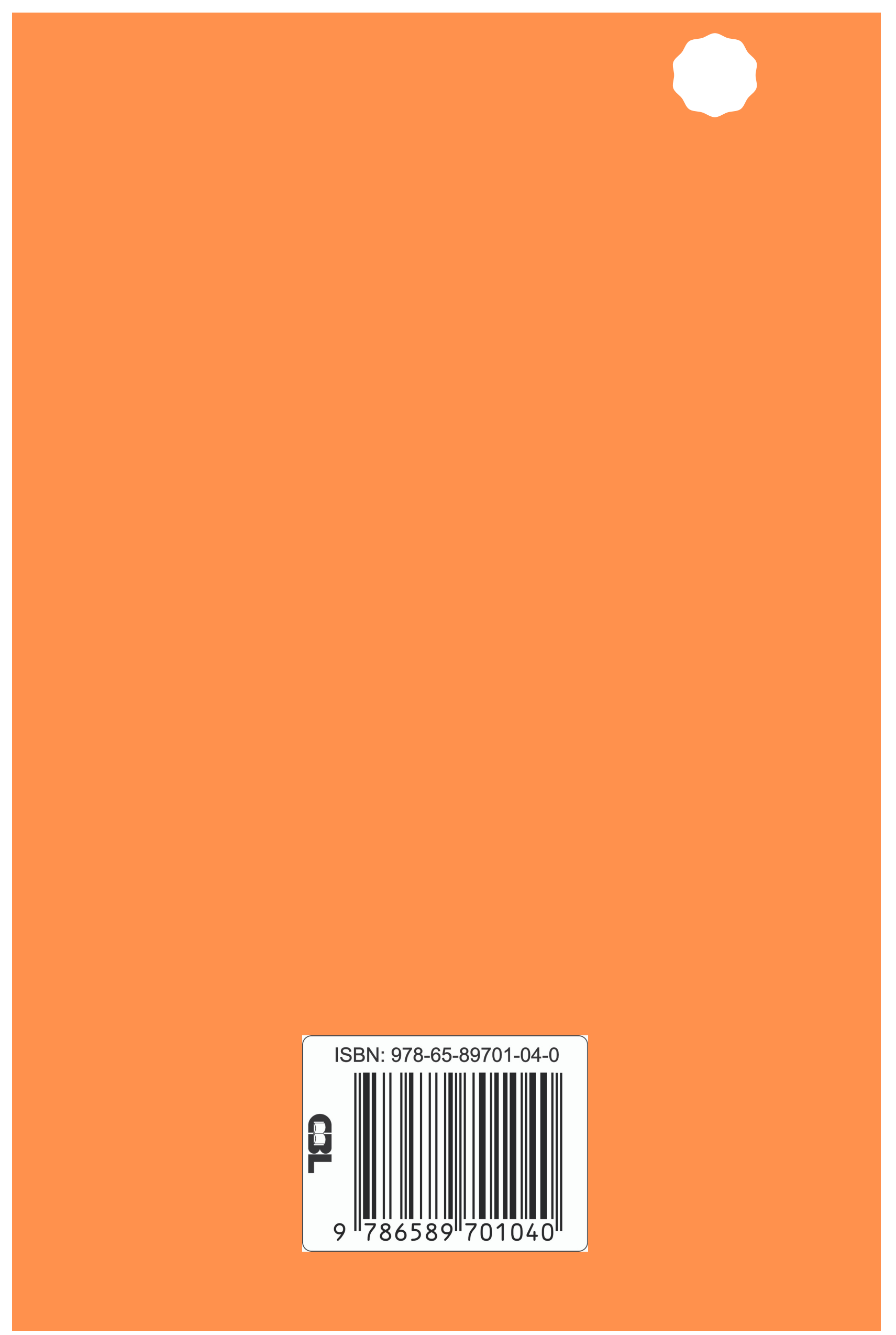

